\title{
Monitoring Managers Through Corporate Compliance Programs*
}

\author{
Charles Angelucci \\ Toulouse School of Economics \\ Email: charles.angelucci@tse-fr.eu
}

\author{
Martijn A. Han \\ Amsterdam Center for Law \& Economics \\ Universiy of Amsterdam \\ Email:m.a.han@uva.nl
}

December 23, 2010

\begin{abstract}
Compliance programs entail monitoring of employees' behavior with the claimed objective of fighting corporate crime. (Competition) Authorities promote such intra-firm monitoring. In a three-tier hierarchy model, authority-shareholder-manager, we study the impact of monitoring on contracting within the firm and the authority's optimal sanctions and leniency policy. We find that compliance programs are beneficial in the fight against corporate crime if and only if the managerial sanction is low. Moreover, when the shareholder blows the whistle, the authority optimally grants partial corporate leniency, while not granting individual leniency to the involved employees. Conversely, when the employee blows the whistle, the authority grants individual leniency if and only if the expected managerial sanction is either particularly high or particularly low. Finally, we find that the authority does not apply a discount on the corporate sanction for the mere fact of having adopted a compliance program. Our results thus contradict the Corporate Leniency Program, Individual Leniency Program and US Sentencing Guidelines on several dimensions.

Keywords: compliance programs, leniency programs, enforcement of the law, antitrust JEL codes: K21, K42, L40

${ }^{*}$ We thank Andrea Attar, Cécile Aubert, Giuseppe Dari-Mattiacci, Bruno Jullien, David Martimort, Jérôme Mathis, Anne Perrot, Antonio Russo, François Salanié, Maarten Pieter Schinkel, Paul Seabright, Jeroen van de Ven, and Glen Weyl and especially Patrick Rey. We are also grateful to seminar and conference participants in Amsterdam, Giessen, Glasgow (EEA Conference 2010), Istanbul (EARIE 2010), Montpellier (DMM 2010), Paris (AFSE 2010 and CREST-LEI) and Toulouse for helpful discussions and comments.
\end{abstract} Opinions and errors are ours. 


\section{Introduction}

A compliance program $(\mathrm{CP})$ is a corporate scheme entailing (i) education of employees about illegal activities, (ii) monitoring employees' behavior, and (iii) disciplining employees in case of illegal conduct. ${ }^{1}$ Legal scholars advocate such schemes as an effective means to deter corporate crime. ${ }^{2}$ However, we argue that, depending on the extent to which the judicial system targets involved employees, CPs can indeed be helpful to deter corporate crime, but can also entail a perverse feature that actually promotes it. Moreover, we show that the current sanctions and leniency practice towards corporations and involved individuals may be suboptimal when taking into account the existence of CPs.

This paper focuses on the monitoring and disciplining dimensions of $\mathrm{CPs}^{3}$ Examples of monitoring employees are unannounced inspections of documents, email messages and telephone records, as well as lawyers accompanying managers to business meetings (Stephan, 2009). Authorities may regard such monitoring as an effective means to rely on the firm to prevent employees from engaging in corporate crime. However, a credibility issue arises when the illegal act not only benefits the involved employees, but also the firm to which they belong, i.e. the shareholders. In such cases, the (board of) shareholders may not take (serious) measures against the involved employees when an illegal act is uncovered. They may even use the obtained information to reward employees for engaging in illegal acts, while hiding the evidence from the authority.

To address this credibility issue, we build a three-tier hierarchy, authority-shareholdermanager and define a compliance programme as a monitoring technology. The shareholder owns the firm and pays the manager to run it. The manager can unobservably breach the law, resulting in a personal benefit while stochastically increasing the shareholder's profit this gives rise to the credibility issue of relying on the shareholder to control her manager. The shareholder can adopt a CP to monitor whether the manager breaches the law, which brings about hard evidence of the breach with some probability. The shareholder and the manager both have the opportunity to blow the whistle and report evidence to the authority, whose objective is to deter breaches at the lowest possible cost. After a report, the authority imposes sanctions on the shareholder and the manager; otherwise, the authority audits the firm with some costly probability and imposes sanctions if it uncovers a breach. Sanctions

\footnotetext{
${ }^{1}$ See 2008 US Sentencing Guidelines $§ 8 B 2.1$ at http://www.ussc.gov/2008guid/tabcon08_1.htm, consulted in October 2009.

${ }^{2}$ See, for example Webb and Molo (1993) and Langevoort (2002). Also, if a CP deters illegal conduct, it allows corporations to avoid being exposed to lengthy litigation and costly sanctions. Moreover, even if a CP fails to deter illegal conduct, but allows the corporation to uncover it before the authority does, the firm can apply for leniency (if available).

${ }^{3}$ We do not consider the educational aspect of CPs. For many serious corporate crimes, such as price fixing by cartels or tax evasion, employees know that such behavior is illegal and need not be educated.
} 
are contingent on (i) whether the shareholder or the manager blew the whistle - thus allowing for corporate and individual leniency -, and (ii) whether a CP was adopted - thus allowing for a discount on the sanction for having implemented a CP.

Our work applies to the field of antitrust law enforcement. We thus explicitly comment on the impact of the existence of CPs on the sanction policy outlined in the US Sentencing Guidelines, as well as the effectiveness of the Corporate Leniency Program and Individual Leniency Program. However, our analysis applies more broadly to any type of corporate crime, or non-compliance with a binding standard, that benefits both the organisation and the involved individual; examples include misselling of a product, tax evasion, cooking the books and environmental fraud. ${ }^{4}$

Desirability of compliance programs. The adoption of a CP reduces information asymmetries within the firm. ${ }^{5}$ The shareholder is then not only able to more cheaply prevent the manager to breach the law (beneficial for social welfare), but potentially also to more cheaply induce the manager to breach (detrimental for social welfare). We find that the adoption of a CP is beneficial for social welfare if and only if the managerial sanction is low. The reason is that if the managerial sanction is lower than the individual gain from breaching the law, then the shareholder pays a positive information rent to prevent a breach, but no information rent to induce it. A CP would then reduce the salary to prevent a breach, while not affecting the salary to induce it, thereby making a breach relatively less profitable for the shareholder.

A symmetric reasoning suggests that if the managerial sanction is high, a CP can make corporate crime actually relatively more profitable for the shareholder. Although we do not want to make the claim that firms adopt CPs with the only objective to reduce information asymmetries so as to promote its employees to misbehave, the result does however suggest a potential perverse effect of increasing the monitoring of harmful activities.

Corporate Leniency Program. Under the US and EU Corporate Leniency Program, if the corporation blows the whistle, both the corporation and the involved individual receive full immunity from legal sanctions. Such a 'blanket' covering the entire corporation and its employees has the objective to incentivise employees to report illegal acts to superiors, so as to file for leniency together (Hammond, 2004). In our model, however, the authority grants

\footnotetext{
${ }^{4}$ Our three-tier hierarchy could thus have alternative interpretations, such as authority - seller of a product - salesman (see Inderst and Ottaviani, 2009), authority - seller of a financial product - broker, or society lender - entrepreneur.

${ }^{5}$ In Price Waterhouse Coopers' Global Economic Crime 2009 Survey, the share of firms responding that they have "suffered" from an economic crime committed by an employee raises with firm size; this may indicate that information asymmetries indeed matter when controlling employees' behavior with regards to corporate crime.
} 
partial immunity to the shareholder when she blows the whistle, while not granting leniency to the manager. Three arguments drive this result.

First, corporate leniency increases the effectiveness of CPs to fight corporate crime. The reason is that corporate leniency incentivises the shareholder to report evidence uncovered through a $\mathrm{CP}$ to the authority, resulting in a sure managerial sanction. Thus, the combination of corporate leniency and the adoption of a $\mathrm{CP}$ increases the expected managerial fine, which in turn disincentives the manager to breach the law, thereby reducing the salary to prevent a breach while increasing the salary to induce a breach. Hence, in the presence of a CP, corporate leniency increases (reduces) the salary cost of inducing (preventing) a breach, thereby making it relatively more profitable for the firm to prevent corporate crime.

Second, although corporate leniency increases the effectiveness of CPs to fight corporate crime, the reduction in the corporate fine also makes a breach less costly to the shareholder. The authority optimally balances this tradeoff by providing 'just enough' leniency to incentivise the shareholder to blow the whistle whenever she possesses evidence. Hence, the authority grants partial corporate leniency.

Third, the authority does not grant leniency to the manager when the shareholder blows the whistle. The reason is that such leniency would reduce the managerial fine, thereby incentivising the manager to breach the law and thus aligning the manager's incentives with those of a shareholder that wants an infringement to occur.

Individual Leniency Program. Under the US Individual Leniency Program, the involved employee receives full immunity from legal sanctions when blowing the whistle. In our model, however, the authority not always grants full individual leniency. The reason is that individual leniency makes breaching the law less costly for the manager, because the managerial fine is reduced. Granting individual leniency then entails the tradeoff that (i) it requires a high salary to induce a breach, because the shareholder must compensate (bribe) the manager not to file for leniency, but (ii) it also requires a high salary to prevent a breach, because the shareholder must pay the manager not to 'breach and blow the whistle' instead of 'not breaching'. We find that the authority grants individual leniency if and only the expected managerial fine is either particularly high or particularly low. Also, whenever individual leniency is granted, the firm is fully sanctioned.

$\mathrm{CP}$ and fine reduction. According to the US Sentencing Guidelines, a firm engaged in illegal behavior is legible to receive a reduced sanction if a $\mathrm{CP}$ was in place at the time of the infringement. In our model, however, such a clause has a perverse effect. As outlined above, we find that the shareholder receives a reduced sanction (partial leniency) for having 
adopted a CP and blowing the whistle, not for the mere act of adopting a CP. The reason is that a CP can be used to more effectively prevent a breach, but also to induce a breach (see above); thus, the very act of implementing a CP is not informative of the shareholder's intentions.

We proceed by discussing related literature in Section 2. Section 3 presents the model. Section 4 solves the model by determining (i) the impact of a CP on salary costs, (ii) optimal sanctions and corporate leniency policy, and (iii) the authority's equilibrium audit probability, thereby deriving conditions under which CPs are helpful in the fight against corporate crime. Section 5 extends the model to allow for individual leniency. Section 6 discusses the policy implications of our model. Section 7 concludes.

\section{Related Literature}

Our work relates to three strands of literature: managerial incentives with harmful activities, leniency programs, and optimal liability rules. To the best of our knowledge, the papers in these literatures consider two-tier hierarchy games: either (i) the authority and the black boxed corporation are strategic players, abstracting away from games within the firm, or (ii) the firm owner (principal) and the employee (agent) are strategic players, with the authority assumed to be an exogenous technology. ${ }^{6}$ We take a step beyond these models by considering a three-tier hierarchy game: the authority, principal and agent are all strategic players.

Managerial incentives with harmful activities. In any model opening the black box of the firm, the nature of the employment contract is central to the analysis. Scharfstein (1988) and Schmidt (1997) study the manager's incentives to exert effort, taking into account the degree of competition in the industry. In Fershtman and Judd (1987), Sklivas (1987) and Spagnolo (2000), an owner offers the manager a publicly observable and binding contract as a commitment device to soften competition or even to sustain tacit collusion. Hiring a manager with strong preferences for income smoothing serves a similar purpose in Spagnolo (2005). These models thus show how an employment contract might be deliberately used by an employer to reach a socially sub-optimal outcome. ${ }^{7}$

\footnotetext{
${ }^{6}$ A notable exception being Inderst and Ottaviani (2009).

${ }^{7}$ Empirical anecdotes hint in the same direction. Price Waterhouse Coopers's Global Economic Crime 2009 Survey states that the main motivation driving employees to commit fraud is "incentives and pressure" such as bonuses, financial targets and fear of losing jobs. Also, Khanna (1996) notes that "shareholders can influence the behavior of corporation managers and employees in a number of way, such as by modifying employment contracts".
} 
From a different perspective, Inderst and Ottaviani (2009) model a seller of a good contracting with an agent to prospect for consumers as well as to provide advice concerning the suitability of the product to the consumer's needs. The consumer is taken to be a fully rational and strategic player. The employment contract, taken to be soft private information as in our model, determines the degree of misselling occurring at equilibrium.

These models however do not consider the authority as a fully-fledged strategic player - if included in the model at all. Aubert (2009) does take into account a strategic authority and is probably the closest paper we relate to. She investigates the impact of employment contracts on the incentives for managers to unobservably substitute productive effort with price fixing. In her model, as in ours, the bonus scheme (i) is soft private information to insiders and can be deliberately used by the principal to induce an illegal activity, and (ii) takes into account that cartelisation leads to evidence being created, possibly resulting in public intervention by the authority. In our model, unlike Aubert's, in addition to the authority's intervention, internal contracting is potentially also affected by the presence of a CP: the principal contracts on profits, evidence generated by the CP and, potentially, evidence brought forward by the employee himself.

Leniency programs. In this paper, both the employee breaching the law and the employer may file for (endogenous) leniency from legal sanctions, ${ }^{8}$ where the employer can come into possession of evidence either through a $\mathrm{CP}$, or through a report by the employee. Our paper thus relates to the literature that studies mechanisms incentivising wrongdoers to self report. To our knowledge, most work considering such 'leniency programs' focuses on antitrust and, in particular, on cartels. Motta and Polo (2003) and Chen and Rey (2006), for instance, show that leniency programs can have two opposing effects: they destabilise existing collusion by increasing the incentives to deviate from the collusive agreement, but also make collusion ex-ante more profitable by reducing the expected sanction. ${ }^{9}$

In contrast to these papers, we study leniency programs that potentially jeopardise a conspiracy vertically within the firm, rather than horizontally between firms. The resulting effects are different. On the one hand, granting leniency to an employer reduces the expected corporate sanction, which incentivises the employer to blow the whistle. This in turn increases the expected managerial sanction, which allows for a reduction in salary costs necessary to prevent corporate crime, while increasing salary costs necessary to induce it. On the other hand, granting leniency to an employee reduces the expected managerial sanction, thereby

\footnotetext{
${ }^{8}$ See Muller (2009) for recent empirical results concerning the efficacy of leniency programs in the US.

${ }^{9}$ Moreover, Harrington (2008) shows that a third force is present when a time varying probability of conviction is considered: as all players rush to apply for leniency, but only one comes first, overall sanctions may end up being higher.
} 
increasing salary costs to ensure that the manager does not blow the whistle. This leads to vertical destabilisation, which parallels horizontal destabilisation in, for example, Spagnolo (2003) who shows that the authority should grant leniency only to the first horizontal party blowing the whistle. Similarly, we argue that leniency should apply only to the first vertical party blowing the whistle, i.e. either the employer or the employee.

Aubert, Kovacic and Rey (2006) (AKR) consider a set-up in which the firm (principal) itself commits the crime, but employees have information about the crime. They argue that it might be optimal to reward employees for blowing the whistle in order to worsen firms' internal incentives. ${ }^{10}$ In contrast, in our model the employee (agent) is the individual possibly breaching the law. The force identified by AKR (2006) is then present, that is, an employer wishing her employee to breach the law must commit to a higher wage to keep him silent. However, there is another side of the coin: granting leniency to an employee increases his incentives to breach the law in the first place, making it more difficult for a firm to deter misconduct. ${ }^{11}$ Thus, we find that individual leniency (or: individual rewards) is not always the optimal policy and depends on the manager's private benefit resulting from the crime.

Optimal liability rules. Our paper also relates to the literature investigating to which extent firms and individuals should be liable for corporate crime. ${ }^{12}$ Sykes (1984) and Segerson and Tietenberg (1992), for instance, consider types of corporate crime that hurt the firm; they argue that, in the presence of agency costs, the authority targeting individuals directly is more effective than targeting the firm. We find that if the authority offers corporate leniency, then targeting individuals generally works better at reducing public enforcement costs than targeting the firm, regardless of agency costs. However, since we consider types of corporate crime that actually benefits the corporation, some degree of corporate liability is always needed, which contrasts Segerson and Tietenberg (1992). ${ }^{13}$

Polinsky and Shavell (1993) and Shavell (1997) call for managerial legal sanctions as the firm itself might be limited in its capacity to punish its employees. In our model, where the employer can actually punish its employees in the form of foregone bonuses, it is preferable to have managerial legal sanctions for an additional reason: the employer cannot be trusted to take appropriate measures as the illegal act itself benefits the employer. Focusing on managerial incentives to form cartels, Stephan (2009) argues that CPs may be ineffective if employees bear no liability, because then employees commit the crime anyway. Our

\footnotetext{
${ }^{10}$ Such individual rewards also provide incentives to individuals to retain evidence.

${ }^{11}$ Aubert (2009), also considering individual leniency programs, identifies this trade-off as well.

${ }^{12}$ See Khanna (1996) for an exposition of the various liability regimes.

${ }^{13}$ The threat of corporate sanctions effectively forces firms to internalise the potential social harm caused by their employees, thereby (at least partially) delegating the task of fighting corporate crime to the firm. Firms may thus choose to monitor employees by adopting a CP.
} 
results differ; we find that CPs are actually most useful when employees bear no liability, because then employers can use the information obtained through the CP to internally punish employees.

When the probability of conviction increases with the amount of internal monitoring, Arlen (1994) identifies a potentially perverse effect of holding firms liable. Improved internal monitoring would then lead to the firm to expose itself to heavy sanctions. As a result, the firm might be reluctant to disclose evidence and/or to choose the right level of monitoring. Our model eliminates this effect by allowing for corporate leniency, which reduces the expected corporate sanction when the firm monitors and reports when evidence is found. In equilibrium, the authority grants partial corporate leniency so as to take away Arlen's perverse effect, while not reducing the fine by too much. Such a corporate leniency policy thus incentivises firms to fight corporate crime by monitoring employees through a $\mathrm{CP}$.

\section{Set-up of the Model}

In this section, we present the set-up of the model.

Outline \& players. Consider the following three-tier hierarchy: an owner of the firm (principal) contracts with a manager (agent) who runs the firm and possibly breaches the law. An authority aims at deterring breaches of the law. The manager does not (Section 4) or does (Section 5) possess evidence of the breach, while the principal may receive evidence either directly through the manager or through monitoring the manager with a $\mathrm{CP}$. The manager and/or the principal can blow the whistle and report evidence to the authority, which then imposes corporate and managerial fines. If no report is made the authority commits to auditing the firm with probability $\beta$ and imposes fines when a breach of the law is uncovered. See Figure 1 for a schematic representation.

All players are risk neutral. We refer to the manager (agent) in the male form (he/his), the owner (principal) in the female form (she/her), and the authority in the neutral form (it/its). 


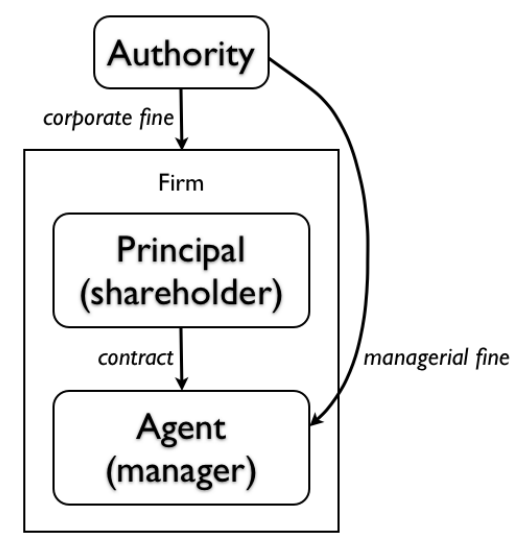

Figure 1. The players: authority, principal (shareholder) and agent (manager).

The manager's action. The manager unobservably takes action $a \in\{b, n\}$, where $b$ is breaching the law and $n$ is not breaching the law. The manager's action stochastically affects the realisation of firm profit $\pi \in\{0,1\}$. The probability distribution over firm profit $\pi$, given action $a$, is depicted in the following table, where $\rho_{\pi}>\frac{1}{2}$, that is, breaching the law increases the firm's expected profit.

\begin{tabular}{|l|c|c|}
\hline & $a=b$ & $a=n$ \\
\hline$\pi=1$ & $\rho_{\pi}$ & $1-\rho_{\pi}$ \\
\hline$\pi=0$ & $1-\rho_{\pi}$ & $\rho_{\pi}$ \\
\hline
\end{tabular}

In Section 4 we consider the case in which the manager does not possess evidence when he breached the law. Section 5 solves the case when the manager does possess evidence, which he may report to her principal or to the authority; details about this adapted set-up are outlined in that section.

The principal's actions. The principal takes three possible actions: (i) she offers the manager a take-it-or-leave-it employment contract inducing action $n$ or $b$, (ii) she chooses whether to adopt a CP, and (iii) she chooses whether or not to report evidence to the authority ('blow the whistle') if she comes into possession of such evidence. Regarding the latter two actions, the principal has the following three 'compliance strategies': she either does not adopt a $\mathrm{CP}(i=N)$, adopts a $\mathrm{CP}$ and reports whenever possible $(i=R)$, or adopts a $\mathrm{CP}$ and never blows the whistle $(i=C)$.

Adopting a $\mathrm{CP}$ allows the principal to uncover perfectly informative hard evidence of a breach with probability $\rho_{\sigma}$. She observes the realisation of the signal $\sigma \in\{0,1\}$, where $\sigma=1$ 
means evidence and $\sigma=0$ means no evidence. The probability distribution over signal $\sigma$, given action $a$ taken by the manager, is depicted in the following table. ${ }^{14}$

\begin{tabular}{|l|c|c|}
\hline & $a=b$ & $a=n$ \\
\hline$\sigma=1$ & $\rho_{\sigma}$ & 0 \\
\hline$\sigma=0$ & $1-\rho_{\sigma}$ & 1 \\
\hline
\end{tabular}

For simplicity, we assume that a CP is costless to implement. Based on an earlier version of the model, we however discuss the results we would obtain if this was not the case in the concluding remarks.

Consider now the employment contract. The principal offers the manager a take-itor-leave-it contract, which defines transfers $t_{\pi, \sigma}$ contingent on (i) the realisation of profit $\pi \in\{0,1\}$ and (ii) the realisation of signal $\sigma \in\{0,1\}$ (if a CP is in place). ${ }^{15}$ The principal may thus use the contract to either induce or to prevent her manager to breach the law.

The employment contract is assumed to be soft private information. We assume that the principal can credibly commit to making the transfers as stated in the employment contract. Furthermore, we do not assume that the principal can credibly commit to a specific reporting strategy, though she would prefer to. ${ }^{16}$ In the concluding remarks, we discuss the results we would obtain if she could commit on that dimension as well.

The transfers $t_{\pi, \sigma}$ are associated with four possible states of nature $\{\pi, \sigma\}$. The following table states the probabilities $p_{\pi, \sigma}^{a, i}$ of these states of nature occurring, given the manager's action $a \in\{b, n\}$ and the shareholder's choice $i \in\{N, C, R\}$.

\begin{tabular}{|l|l|l|}
\hline $\begin{array}{l}\text { StATE OF NATURE }\{\pi, \sigma\} \text { AND } \\
\text { ASSOCIATED TRANSFER } t_{\pi, \sigma}\end{array}$ & ProbABILITy IF $a=n$ & ProbABILITy IF $a=b$ \\
\hline$\{\pi=1, \sigma=1\}, t_{11}$ & $p_{11}^{n, i}=0$ & $p_{11}^{b, i}=\rho_{\pi} \rho_{\sigma}^{i}$ \\
\hline$\{\pi=1, \sigma=0\}, t_{10}$ & $p_{10}^{n, i}=1-\rho_{\pi}$ & $p_{10}^{b, i}=\rho_{\pi}\left(1-\rho_{\sigma}^{i}\right)$ \\
\hline$\{\pi=0, \sigma=1\}, t_{01}$ & $p_{01}^{n, i}=0$ & $p_{01}^{b, i}=\left(1-\rho_{\pi}\right) \rho_{\sigma}^{i}$ \\
\hline$\{\pi=0, \sigma=0\}, t_{00}$ & $p_{00}^{n, i}=\rho_{\pi}$ & $p_{00}^{b, i}=\left(1-\rho_{\pi}\right)\left(1-\rho_{\sigma}^{i}\right)$ \\
\hline
\end{tabular}

\footnotetext{
${ }^{14}$ See Tirole (1986) for the same signal structure. For simplification, we assume that a CP possibly gives rise to hard information. It the principal were to possess soft information and transmit it to the authority, then an investigation would still be needed as judges and courts are reluctant to rely on testimonies which are not backed by factual evidence. The possibility of soft information is left for future work.

${ }^{15}$ Note that the principal cannot contract on the outcome of the authority's audit. By introducing such an incompleteness we replicate the same results that would obtain in a frictionless contracting environment in which the authority commits type I/II errors (though not too frequently). If completeness was restored in the current framework, most results would qualitatively hold but less "forces" would be at play.

${ }^{16}$ We thus adopt the conventional wisdom that the logic behind bonuses is opaque to outsiders, but perfectly understandable to insiders. We also assume that that such bonuses are credible as they involve relatively small amounts of money. Committing to reporting/ not reporting an employee, however, may involve colossal amounts of money and is thus taken to be credible only if rational ex post.
} 
where $\rho_{\sigma}^{i}=\rho_{\sigma}$ if $i=C, R$ and $\rho_{\sigma}^{i}=0$ if $i=N$.

The authority's action. The authority possibly imposes corporate fine $F^{i}$ on the principal and individual (managerial) fine $f^{i}$ on the manager, subject to legal caps $\bar{F}$ and $\bar{f}$, respectively. If the principal blows the whistle, the authority imposes sanctions $F^{R}$ and $f^{R}$. If instead no report is made, the authority commits ${ }^{17}$ to audit the firm with probability $\beta$, in which case it always uncovers the beach if it occurred. ${ }^{18}$ The authority then imposes sanctions $F^{C}$ and $f^{C}$ when a CP was in place, or sanctions $F^{N}$ and $f^{N}$ when a CP was not in place.

Information. All actions are publicly observable, except whether the manager breaches the law or not, which is unobservable to both the principal and the authority. When the principal and the manager contract with each other, the manager knows whether the principal has adopted a CP.

Whether the principal uncovers evidence through the adoption of a $\mathrm{CP}$ is observable to the manager, but unobservable to the authority; only if the principal blows the whistle then the authority knows that the principal has found evidence.

\section{Payoffs.}

Principal. The principal receives realised firm profit $\pi \in\{0,1\}$ and pays managerial salary $t_{\pi, \sigma}$. If the manager breached the law, the firm faces expected corporate fine $E_{i}[F]$, where

$$
\begin{aligned}
& E_{N}[F]=\beta f^{N}, \\
& E_{C}[F]=\beta f^{C}, \\
& E_{R}[F]=\underbrace{\rho_{\sigma} F^{R}}_{A}+\underbrace{\left(1-\rho_{\sigma}\right) \beta F^{C}}_{B} .
\end{aligned}
$$

The expected corporate fine when the principal reports evidence, consists of two parts: (A) with probability $\rho_{\sigma}$ the principal finds evidence and blows the whistle, resulting in fine $F^{R}$, while $(\mathrm{B})$ with probability $1-\rho_{\sigma}$ the principal finds no evidence, after which the authority investigates the firm, resulting in expected fine $\beta F^{C}$. Thus, the principal's expected payoff $\Pi^{a, i}$ - given the principal's compliance strategy $i \in\{N, C, R\}$, the transfers stated in the

\footnotetext{
${ }^{17}$ If the antitrust authority cannot credibly commit to a probability of investigation, the equilibrium is in mixed strategies - see for instance Khalil (1997).

${ }^{18}$ Spagnolo (2003), Aubert, Kovacic and Rey (2006) and Aubert (2009) also make the assumption that an audit always leads to conviction if a breach occurred.
} 
employment contract $t_{\pi, \sigma}$, and the manager's actions $a \in\{n, b\}-$ is

$$
\Pi_{i}^{a}=E_{a}[\pi]-E_{i}\left[t^{a}\right]-\mathbf{I}(a) E_{i}[F]
$$

where $\mathbf{I}(a)=1$ if $a=b$ and $\mathbf{I}(a)=0$ if $a=n$.

Manager. The agent receives his salary $t_{\pi, \sigma}$. When breaching the law, she receives private gain $G,{ }^{19}$ but faces expected managerial fine $E_{i}[f]$, where $E_{N}[f]=\beta f^{N}, E_{C}[f]=\beta f f^{C}$, and $E_{R}[f]=\rho_{\sigma} f^{R}+\left(1-\rho_{\sigma}\right) \beta\left(1-\rho_{\sigma}\right) \beta f^{C}$. The manager has a zero outside option and is protected by limited liability with respect to salary, but not with respect to the managerial fine. Thus, the manager's expected payoff $A^{a, i}$ - given the principal's compliance strategy $i \in\{N, C, R\}$, the transfers stated in the employment contract $t_{\pi, \sigma}$, and the manager's actions $a \in\{n, b\}-$ is

$$
A_{i}^{a}=E_{i}\left[t^{a}\right]+\mathbf{I}(a)\left(G-E_{i}[F]\right)
$$

Authority. The authority's cost of auditing firms is $K(\beta)$, where $K^{\prime}(\beta)>0$. Fines are costless to impose and collect. We assume that breaches are so detrimental to society that the authority's objective is to minimise audit cost $K(\beta)$ subject to breaches being deterred, i.e.

$$
\begin{aligned}
& \min _{\beta,\left\{F^{R}, F^{N}, F^{C}\right\},\left\{f^{R}, f^{N}, f^{C}\right\}} K(\beta) \text { s.t. } \\
& \quad \max \left\{\Pi_{N}^{n}, \Pi_{C}^{n}, \Pi_{R}^{n}\right\} \geq \max \left\{\Pi_{N}^{b}, \Pi_{C}^{b}, \Pi_{R}^{b}\right\},
\end{aligned}
$$

where constraint (2) ensures that the principal writes an employment contract that prevents her manager to breach, that is, the principal's expected payoff when inducing a breach (RHS) must not be higher than her payoff when preventing a breach (LHS). ${ }^{20}$

Timing. The timing of the game is as follows and schematically depicted in Figure 2:

1. The authority sets its policy parameters $\beta,\left\{F^{R}, F^{C}, F^{N}\right\},\left\{f^{R} f^{C}, f^{N}\right\}$;

2. The principal chooses her compliance strategy, $i \in\{R, C, N\}$;

3. The principal offers a take-it-or-leave-it contract to the manager, which the manager accepts or rejects;

\footnotetext{
${ }^{19}$ Managerial private gain $G$ can be interpreted either as (i) benefits directly resulting from the breach, or (ii) benefits indirectly resulting from the breach, such as the possibility to work less hard. For example, in Aubert (2009), managerial effort and cartelisation are strategic substitutes: forming a cartel allows the manager to exert less costly effort, which is an indirect benefit.

${ }^{20}$ Another interpretation of this objective function is that the authority executes a pre-written law at the least possible costs.
} 
4. The manager breaches the law or not, $a \in\{n, b\}$;

5. Firm profit $\pi \in\{0,1\}$ and signal $\sigma \in\{\emptyset, 1\}$ are realised;

6. If evidence of breach is available $(\sigma=1)$, the principal blows the whistle if and only if $i=R ;^{21}$

7. If the authority receives a report of evidence, the authority imposes sanctions. If the authority receives no report of evidence, the authority audits the firm with probability $\beta$ and imposes sanctions when there was a breach.

8. The employment contract is executed. ${ }^{22}$

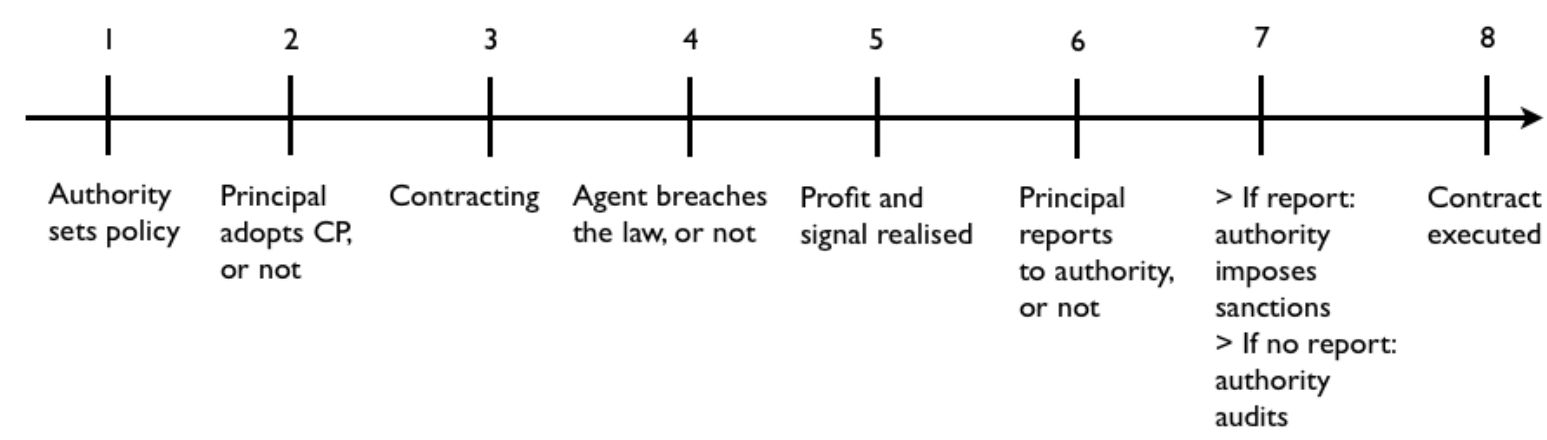

Figure 2. Timing of the game.

\section{Manager Does not Possess Evidence}

This section solves the model for the case in which the manager does not possess evidence when he breached the law. In subsection 4.1, we solve for the expected transfers associated with the optimal employment contracts. Subsection 4.2 solves for the authority's optimal sanctions and leniency policy. Subsection 4.3 derives the impact of compliance programs on the optimal level of auditing necessary to deter corporate crime.

\footnotetext{
${ }^{21}$ We consider reporting to (possibly) happen before the authority's audit, so as to focus on the impact of leniency programs on practices that are not yet under investigation. Motta and Polo (2003) show that it can be efficient to reduce fines even when the antitrust authority has already started an investigation, but has not yet obtained evidence of misbehavior.

${ }^{22}$ Although the employment contract is executed after the possible audit, the contract is not contingent on the outcome of the audit. This assumption is similar in effect to Aubert (2009), who instead assumes that the contract is executed before a possible audit, but managerial whistle blowing (Section 5 of our paper) cannot take place after the contract is executed.
} 


\subsection{Optimal Expected Transfers}

In this subsection, we present the expected transfers associated with the manager's employment contract. We define $\gamma^{N}=\frac{\rho_{\pi}}{2 \rho_{\pi}-1}>1$ and $\gamma^{C}=\frac{\rho_{\pi}}{\rho_{\pi}-\left(1-\rho_{\pi}\right)\left(1-\rho_{\sigma}\right)}>1$ as measures of information asymmetries, where $\gamma^{N}>\gamma^{C}$.

Lemma 1 - No CP If no $C P$ is adopted $(i=N)$, the expected transfer is $E_{N}\left[t^{b}\right]=$ $\max \left\{\gamma^{N}\left(\beta f^{N}-G\right), 0\right\}$ when inducing a breach, and $E_{N}\left[t^{n}\right]=\max \left\{\gamma^{N}\left(G-\beta f^{N}\right), 0\right\}$ when preventing a breach.

Proof. See Appendix A.1.

When the principal wants to prevent (induce) a breach, she pays a positive expected transfer if and only if the manager's gain $G$ from breaching is higher (lower) than the expected managerial fine $\beta f^{N}$, i.e. if and only if the incentives of the principal and the manager are not aligned. This expected transfer is the difference between $G$ and $\beta f^{N}$, inflated by the measure of information asymmetries $\gamma^{N}$, caused by the fact that the only (imperfect) information that the principal has about the manager's behavior is the realisation of profit $\pi$.

Lemma 2 - CP If a $C P$ is adopted $(i=\{C, R\})$, the expected transfer is $E_{i}\left[t^{b}\right]=$ $\max \left\{E_{i}[f]-G, 0\right\}$ when inducing a breach, and $E_{i}\left[t^{n}\right]=\max \left\{\gamma^{C}\left(G-E_{i}[f]\right), 0\right\}$ when preventing a breach, where $E_{C}[f]=\beta f^{C}$ and $E_{R}[f]=\underbrace{\rho_{\sigma} f^{R}}_{A}+\underbrace{\left(1-\rho_{\sigma}\right) \beta f^{C}}_{B}$.

Proof. See Appendix A.1.

First, we note that the expected managerial fine when the principal reports evidence, consists of two parts: (A) with probability $\rho_{\sigma}$ the principal finds evidence which she reports to the authority, resulting in managerial fine $f^{R}$, while (B) with probability $1-\rho_{\sigma}$ the principal finds no evidence, but the authority may still investigate, resulting in expected managerial fine $\beta f^{C}$.

Second, we note that the realisation of the signal $\sigma$ adds to the information at the disposal of the principal, thus decreasing the moral hazard problem. As a result, the measure of information asymmetries decreases from $\gamma^{N}$ to $\gamma^{C}$ when the principal prevents her manager to breach, while information rents disappear altogether when the principal induces her manager to breach as evidence $(\sigma=1)$ is a perfectly informative signal about a breach having occurred.

We again have that the principal pays a positive expected transfer if and only if the incentives of the principal and the manager are not aligned. This expected transfer is the difference between $G$ and $E_{i}[f]$, which is inflated by the measure of information asymmetries $\gamma^{C}$ when the principal prevents a breach. 


\subsection{Optimal Sanctions and Leniency Policy}

In this subsection, we solve for the optimal fines and determine whether and when the authority grants leniency to the principal and/or the manager.

The authority's objective is to minimise $\beta$, by setting (i) the fines $f^{i}$ and $F^{i}$, for $i \in$ $\{N, C, R\}$, and (ii) the audit probability $\beta$, such that the principal does not find it profitable to write down an employment contract that induces her manager to breach, i.e. such that $\max \left\{\Pi_{N}^{n}, \Pi_{C}^{n}, \Pi_{R}^{n}\right\} \geq \max \left\{\Pi_{N}^{b}, \Pi_{C}^{b}, \Pi_{R}^{b}\right\}$, or

$$
\begin{aligned}
& 1-\rho_{\pi}-\min \left\{E_{N}\left[t^{n}\right], E_{C}\left[t^{n}\right], E_{R}\left[t^{n}\right]\right\} \geq \\
& \rho_{\pi}-\min \left\{E_{N}\left[t^{b}\right]+\beta F^{N}, E_{C}\left[t^{b}\right]+\beta F^{C}, E_{R}\left[t^{b}\right]+\rho_{\sigma} F^{R}+\left(1-\rho_{\sigma}\right) \beta F^{C}\right\} .
\end{aligned}
$$

The following Proposition states the optimal fines and leniency policy.

Proposition 1 The authority's optimal policy is to set all fines to their legal maximum, except when the principal reports evidence the authority provides partial corporate leniency, that is,

$$
\begin{aligned}
& \text { (i) } f^{N}=\bar{f}, F^{N}=\bar{F}, \\
& \text { (ii) } f^{C}=\bar{f}, F^{C}=\bar{F}, \\
& \text { (iii) } f^{R}=\bar{f}, F^{R}=\beta \bar{F}-|\epsilon|,
\end{aligned}
$$

where $\epsilon$ is arbitrarily small. ${ }^{23}$

Proof. See Appendix A.2.

Let us discuss the intuition of Proposition 1.

The authority sets all managerial fines to their legal maximum, i.e. $f^{i}=\bar{f}$, for every $i \in\{N, C, R\}$. Increasing the managerial fines leads to (i) a better alignment of the manager's incentives with those of the principal if she prevents a breach, resulting in a lower expected transfer, and (ii) more misalignment between the manager's incentives and those of the principal if she induces a breach, resulting in a higher expected transfer. Thus, increasing the managerial fines relaxes constraint 3: it becomes cheaper for the principal to prevent a breach, but more expensive to induce a breach. As a result, the incentives of the principal become more in line with those of the authority, allowing for less (costly) auditing.

\footnotetext{
${ }^{23}$ We realise that ' $\epsilon$ is arbitrarily small' violates the equilibrium concept since all variables are continuous. However, rewriting the proofs with all variables defined in a discrete grid - which is practically intuitive: monetary values cannot be splitted at some point - solves this.
} 
The authority sets corporate fines to their legal maximum, but grants partial leniency to the principal if she reports evidence. First, we consider the case in which the principal does not adopt a $\mathrm{CP}$ and thus never comes into possession of evidence. In that case, blowing the whistle is not possible; the authority simply sets the corporate fine $f^{N}$ to its legal maximum so as to maximally deter the principal from inducing her manager to breach the law, i.e. $f^{N}=\bar{f}$.

Second, suppose the principal adopts a CP, which possible provides her with evidence. Substituting the optimal managerial fines derived above into $E_{C}[f]$ and $E_{R}[f]$ gives

$$
E_{R}[f]=\left(\rho_{\sigma}+\left(1-\rho_{\sigma}\right) \beta\right) \bar{f}>E_{C}[f]=\beta \bar{f},
$$

that is, the expected managerial fine is higher when the principal reports than if she does not report, because the manager is convicted for sure after a report. Thus, blowing the whistle reduces the expected salary cost to prevent a breach, but increases the expected salary cost to induce a breach. Therefore, a principal preventing a breach would like to commit vis-a-vis her manager to reporting eventual evidence, while a principal inducing a breach would like to commit to not report.

Whether such commitments are credible depends on the relative sizes of the corporate fines: blowing the whistle is ex-post rational for the principal if and only if reporting leads to a lower expected corporate fine than not reporting, i.e. if and only if $F^{R}<\beta F^{C}$. Now, to maximally deter the principal from inducing a breach, the authority sets $F^{C}$ and $F^{R}$ as high as possible, with the restriction that $F^{R}<\beta F^{C}$ so as to provide the breach-preventing principal with the commitment to report, while destroying the breach-inducing principal's commitment to not report. Thus, the authority sets the corporate fine when a CP is implemented to the legal maximum, i.e. $F^{C}=\bar{F}$, while granting partial leniency to the principal when she reports, i.e. $F^{R}=\beta \bar{F}-|\epsilon|$, where $\epsilon$ is arbitrarily small.

\subsection{Social Desirability of Compliance Programs}

Given the authority's optimal sanctions and leniency policy derived in the previous subsection, we now determine the impact of the monitoring technology, the CP, on welfare. From the previous two subsections, we know that adopting a CP has two effects: (i) it decreases information asymmetries within the firm, thereby decreasing information rents, if any, and (ii) it increases the expected managerial fine from $\beta \bar{f}$ to $\rho_{\sigma} \bar{f}+\left(1-\rho_{\sigma}\right) \beta \bar{f}$, because if the principal finds evidence she reports it to the authority to receive partial leniency, resulting in a sure conviction of the manager.

The authority minimises the audit probability, subject to assuring that no breach occurs. 
Let $\beta^{*}$ be this minimum audit probability, which we compare with the minimum audit probability in a hypothetical scenario in which the monitoring technology is not available, $\tilde{\beta}^{*} .^{24}$ In Proposition 2 we state whether the monitoring through CPs is socially desirable $\left(\beta^{*}<\tilde{\beta}^{*}\right)$ or undesirable $\left(\beta^{*}>\tilde{\beta}^{*}\right)$; we graphically illustrate the results in Figure 3. Denote by $F^{\prime}$ and $F^{\prime \prime}$ thresholds of the corporate fine, where $F^{\prime}<F^{\prime \prime}$. We assume that the corporate fine $\bar{F}$ is high enough for $\beta^{*}<1$ to exist.

Proposition 2 If the managerial fine is lower than the manager's private benefit from the breach $(\bar{f}<G)$, monitoring the manager through a compliance program is welfare enhancing. If the managerial fine is higher than the manager's private benefit from the breach $(\bar{f} \geq G)$, monitoring the manager through a compliance program is detrimental for welfare if the corporate fine is low $\left(\bar{F}<F^{\prime}\right)$, welfare neutral if the corporate fine is intermediate $\left(F^{\prime} \leq \bar{F}<F^{\prime \prime}\right)$, and welfare enhancing if the corporate fine is high $\left(\bar{F}>F^{\prime \prime}\right)$.

Proof. See Appendix A.3.

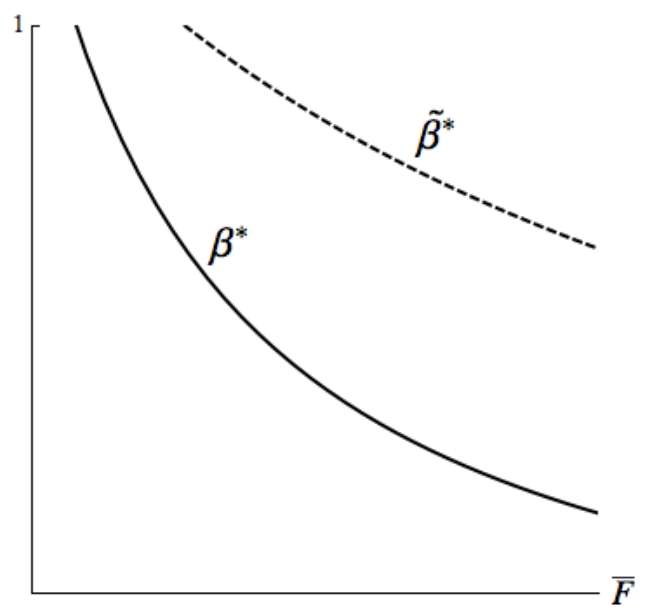

Figure 3a. Low managerial fine: $\bar{f}<G$.

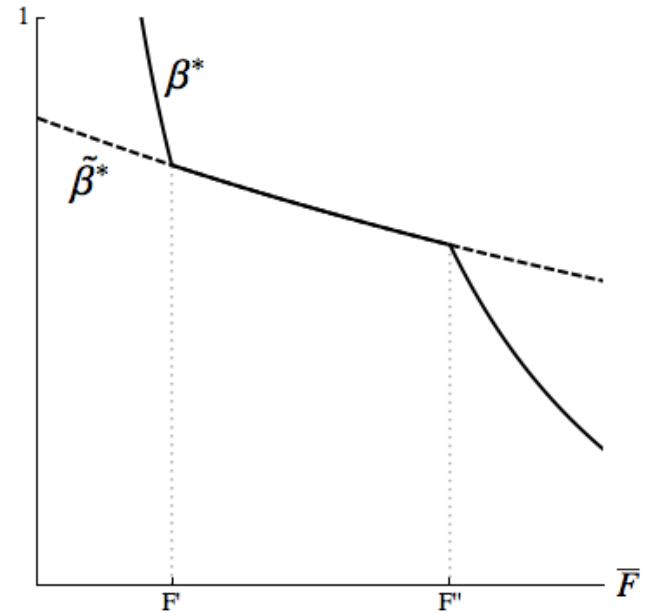

Figure 3b. High managerial fine: $\bar{f}>G$. Audit probability when CPs are available $\beta^{*}$, compared to audit probability when CPs are not available $\tilde{\beta}^{*}$.

\footnotetext{
${ }^{24}$ Such a situation could be due to, for instance, to very high implementation costs, but also to cultural and legal reasons.
} 
Low managerial fine. When the managerial fine is lower than the manager's private benefit from the breach $(\bar{f}<G)$, the manager has private incentives to breach the law when a $\mathrm{CP}$ is not adopted. The principal then pays (i) a zero salary to induce a breach, but (ii) a positive expected salary, including an information rent, to prevent a breach. As discussed in the previous two subsections, adopting a CP has two effects: it decreases (possible) information rents and increases the expected managerial fine. The former effect thus decreases the expected transfer to prevent a breach, while not affecting the zero transfer to induce a breach. The latter effect has a disincentivising effect on the manager to breach, thereby reducing the positive transfer to prevent a breach and (weakly) increasing the zero transfer to induce a breach. Altogether, the adoption of a CP thus reduces the salary cost of preventing a breach, while (weakly) increasing the salary cost of inducing a breach. This makes corporate crime relatively less profitable for the principal, which allows the authority to reduce its costly audit probability.

High managerial fine. Consider now the case in which the managerial fine is higher than the manager's private benefit from the breach $(\bar{f} \geq G)$. In such cases, the manager has private incentives to breach if $\beta \bar{f}<G$, but has no private incentives to breach if $\beta \bar{f} \geq G$. For the following analysis, we note that the corporate fine $\bar{F}$ and the audit probability $\beta$ are substitutes in deterring corporate crime, that is, a high corporate fine allows for a low audit probability.

Suppose the corporate fine is high $\left(\bar{F} \geq F^{\prime \prime}\right)$. By substitutability of $\bar{F}$ and $\beta$, the authority can set the audit probability $\beta$ relatively low. In particular, the audit probability is so low that $\beta \bar{f}<G$, that is, the manager has private incentives to breach. Without a CP, the principal then pays (i) a zero salary to induce a breach, but (ii) a positive expected salary, including an information rent, to prevent a breach. By the same arguments as above ('low managerial fine'), a CP reduces the salary cost of preventing a breach, while (weakly) increasing the salary cost of inducing a breach. This makes corporate crime relatively less profitable for the principal, which allows the authority to reduce its costly audit probability.

Suppose now the corporate fine is not so high $\left(\bar{F}<F^{\prime \prime}\right)$. By substitutability of $\bar{F}$ and $\beta$, the authority needs to set the audit probability $\beta$ relatively high, resulting in $\beta \bar{f}>G$, that is, the manager has no private incentives to breach. Without a $\mathrm{CP}$, the principal then pays (i) a zero salary to prevent a breach, but (ii) a positive expected salary, including an information rent, to induce a breach. Then, adopting a CP by the principal that prevents a breach has no effect on the expected transfer as it is zero anyway.

However, the principal inducing a breach faces a tradeoff: adopting a CP (i) reduces the information rent, which gives a downward pressure on the expected transfer, but (ii) if the 
principal finds evidence she cannot help reporting it to the authority so as to receive partial leniency, which gives an upward pressure on the expected transfer. When the corporate fine is low $\left(\bar{F}<F^{\prime}\right)$, the former effect outweighs the latter ${ }^{25}$ : adopting a $\mathrm{CP}$ then allows the principal to reduce the salary cost of inducing breach, which pushes the authority to increase its costly audit probability to be able to deter corporate crime. Conversely, when the corporate fine is intermediate $\left(F^{\prime} \leq \bar{F}<F^{\prime \prime}\right)$, the latter effect outweighs the former: the principal inducing a breach would not adopt a CP. As a result, the availability of CPs then has no impact on the authority's audit probability.

\section{Individual Leniency}

In this section we study how managerial leniency interacts with the effects of a CP. To that end, we extend our set-up by assuming that if the manager breaches the law he comes into possession of a piece of verifiable evidence, which he can (i) report to the principal $\left(r_{p}=1\right)$ or not $\left(r_{p}=0\right)$, and (ii) report to the authority $\left(r_{a}=1\right)$ or not $\left(r_{a}=0\right)$, where a report to the authority is observed by the principal. This set-up allows the shareholder to condition transfers on such reports. Similarly, the authority conditions fines on the manager blowing the whistle, which we denote by $F^{r}$ and $f^{r}$.

The timing of the game is adapted by taking into account that the manager can make reports either immediately after breaching the law, or after (possibly) payoff relevant information comes available. Figure 4 indicates those stages by 4' and 5', respectively, which we refer to as the 'ex-ante' and 'interim' reporting stages.

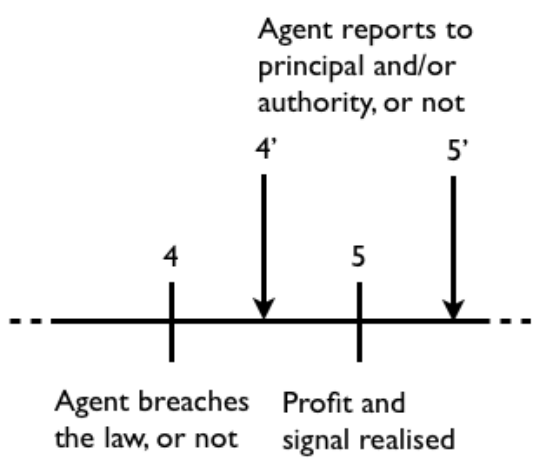

\footnotetext{
${ }^{25}$ The intuition runs as follows. The latter effect (i.e. the difference in the expected managerial fine with and without a $\left.\mathrm{CP}, \rho_{\sigma} \bar{f}+\left(1-\rho_{\sigma}\right) \beta \bar{f}-\beta \bar{f}\right)$ is less pronounced the higher is the audit probability is. The reason is that with a high audit probability, the expected managerial fine is relatively high already without a CP. Now, if the corporate fine is low $\left(\bar{F}<F^{\prime}\right)$, then by substitutability of the corporate fine and the audit probability, we have that the audit probability $\beta$ needs to be relatively high. This reduces the scope of the latter effect.
} 
Figure 4. Revised timing: the manager can report immediately after he breaches (4') or after the realisation of information (5').

The derivation of the equilibrium is tedious and replicates many of the steps taken in the previous section. Therefore, we focus on the results that differ from the previous section. Subsection 5.1 deals with the impact of the adapted set-up on optimal transfers, subsection 5.2 discusses the optimal individual leniency policy, and subsection 5.3 states the impact of the individual leniency policy on the effectiveness of CPs.

\subsection{Optimal Expected Transfers: Reporting Constraints}

Since the manager now holds verifiable evidence of his breach, the principal faces an additional incentive compatibility constraint when offering her employment contract. She must ensure that her manager does not blow the whistle so as to receive managerial leniency. We coin this constraint the reporting constraint and show how it affects the expected transfers. ${ }^{26}$

By the same reasoning as in the previous section, the authority optimally (i) sets the managerial fines $f^{N}, f^{C}$ and $f^{R}$ to their legal maximum $\bar{f}$; (ii) sets the corporate fines $F^{N}$ and $F^{C}$ to their legal maximum $\bar{F}$; and (iii) grants partial leniency when the principal reports evidence to the authority, i.e. $F^{R}=\beta \bar{F}-|\epsilon|$, thereby ensuring that the principal always reports when she has evidence of a breach. The formal proof is delegated to Appendix X.

If the authority grants managerial leniency, the reporting constraint turns up in the contracting problem of the principal inducing a breach, but also in the contracting problem of the principal preventing a breach, thus introducing a tradeoff.

Lemma 3 - PReventing A BREACH If the principal prevents a breach, she adopts a $C P$, resulting in expected transfer $E_{R}\left[t^{n}\right]=\max \left\{\gamma^{C}\left(G-E_{R}[f]\right), G-f^{r}, 0\right\}$.

Proof. See Appendix B.1.

If the principal prevents a breach she adopts a CP, because that (i) decreases the information asymmetry, while (ii) increasing the expected managerial fine. The principal now faces two ICs: she must not only make sure that (i) the manager does not breach, but also that (ii) the manager does not 'breach and report to the authority' so as to possibly receive individual leniency. ${ }^{27}$ This introduces the additional restriction $E_{R}\left[t^{n}\right] \geq G-f^{r}$, that is, the

\footnotetext{
${ }^{26}$ Technically, there are several reporting constraints, because the manager may report to the authority at several points in time during the game. However, these reporting constraints boil down to one relevant constraint that dominates all others - see Appendix B.1.

${ }^{27}$ The strategy "breach and report to the principal" is weakly dominated by the strategy "breach and report to the authority" since $f^{r} \leq f^{R}=\bar{f}$.
} 
expected payment when the manager does not breach is at least as large as the managerial gain $G$ when she breaches minus the managerial fine when she blows the whistle $f^{r}$.

The principal may induce a breach of the law in three different ways, as stated in the following Lemma.

Lemma 4 - INDUCING A BREACH If the principal induces a breach without adopting a $C P$, the expected transfer is

$$
E_{N}\left[t^{b}\right]=\underbrace{\max \left\{\gamma^{N}(\beta \bar{f}-G), 0\right\}}_{A}+\underbrace{\max \left\{\beta \bar{f}-f^{r}, 0\right\}}_{B} .
$$

while if she instead adopts a CP and respectively requests or does not request evidence, it is

$$
\begin{aligned}
& E_{R}\left[t^{b}\right]=\max \{\underbrace{\bar{f}-G}_{E}, \underbrace{\bar{f}-E_{R}[f]}_{F}, \underbrace{\bar{f}-f^{r}}_{G}, 0\}, \\
& E_{R}\left[t^{b}\right]=\max \{\underbrace{E_{R}[f]-G+\max \left\{\beta \bar{f}-f^{r}, 0\right\}}_{C}, \underbrace{E_{R}[f]-f^{r}}_{D}, 0\} .
\end{aligned}
$$

Proof. See Appendix B.2.

The principal must ensure that the manager (i) breaches the law, (ii) does not blow the whistle immediately after having breached, and (iii) does not blow the whistle after the realisation of payoff relevant information, such as profit $\pi$ or signal $\sigma{ }^{28}$

Suppose the principal does not adopt a CP. She then induces a breach by rewarding the manager if profit is high $(\pi=1)$, resulting in payment $A$. She must also reward the manager for not blowing the whistle at any time, resulting in additional payment $B$. Payment $B$ comes in addition to $A$ as it is paid to the manager for being silent, that is, it is being paid to the manager if he breaches the law and stays silent, but also to the manager not breaching the law as he has nothing to confess and thus stays silent automatically.

Suppose now the principal adopts a CP. If she does not request evidence from the manager, payment $C$ ensures that the manager breaches the law and does not blow the whistle immediately, while payment $D$ ensures that the manager does not blow the whistle after the realisation of signal $\sigma=0$. If she does request to see evidence, she rewards the manager if and only if he hands in evidence and does not blow the whistle. Noting that the principal cannot help to blow the whistle when she possesses evidence, the expected transfer must

\footnotetext{
${ }^{28}$ The strategy "adopt no CP and request evidence" entails a weakly higher expected transfer than the strategy "adopt a CP and request evidence" and is therefore weakly dominated - see Appendix B.2.5.
} 
ensure that the manager does not (i) "not breach" $(E)$, (ii) "breach and report no evidence to the principal" $(F)$, and (iii) "breach and blow the whistle" $(G)$.

The following Lemma qualitatively summarises the findings from Lemmas 3 and 4 .

Lemma 5 Allowing for individual leniency weakly increases the expected transfer both to induce and to prevent a breach of the law.

Proof. Comparing Lemmas 1 - 4 straightforwardly shows that the introduction of the reporting constraints weakly increases the expected transfers.

The authority faces a tradeoff when granting leniency to the manager: the reporting constraint weakly increases the expected transfer both to induce and to prevent a breach. Indeed, by Lemmas 3 and 4, individual leniency (i) weakly increases the expected transfer to induce a breach as the principal must compensate the manager to stay silent in stages 4 ' and 5', but (ii) also weakly increases the expected transfer to prevent a breach as the principal must compensate the manager to not "breach the law and blow the whistle".

\subsection{Individual Leniency Policy}

Provided the tradeoff faced by the authority, the following Proposition states the optimal individual leniency policy. For sake of brevity, we here focus on the case in which monitoring through a $\mathrm{CP}$ is relatively precise, i.e. $\rho_{\sigma}>\left(1-\rho_{\pi}\right) / \rho_{\pi} \cdot{ }^{29}$

Proposition 3 There exist thresholds $\tilde{f}$ and $\tilde{\tilde{f}}$, where $\tilde{f}<\tilde{\tilde{f}}$, and thresholds $\tilde{F}$ and $\tilde{\tilde{F}}$, such that if the cap on the managerial fine $\bar{f}$ is

1. lower than $\tilde{f}$ then the authority grants individual leniency, regardless of $\bar{F}$,

2. between $\tilde{f}$ and $\tilde{\tilde{f}}$ then the authority grants individual leniency if and only if $\bar{F}<\tilde{F}$,

3. higher than $\tilde{\tilde{f}}$ then the authority grants individual leniency if and only if $\bar{F}<\tilde{\tilde{F}}$.

Proof. See Appendix C.

First, suppose $\bar{f}<\tilde{f}$. For such low values of the managerial fine, the manager's private incentive to breach the law $G-\beta \bar{f}$ is relatively large. Therefore, absent individual leniency, it is very costly for the principal to prevent a breach, while it is costless to induce one. As a result, introducing the reporting constraint has either no impact or a very small impact on

\footnotetext{
${ }^{29}$ Results concerning the other cases are very similar and can be provided on request.
} 
the expected transfer to prevent a breach, while it increases the expected transfer to induce a breach by a lot. Therefore, the authority optimally grants individual leniency.

Second, suppose $\tilde{f}<\bar{f}<\tilde{\tilde{f}}$. Absent individual leniency, it is still costless to induce a breach but now also relatively cheap to prevent one. Consequently, granting individual leniency strictly increases both transfers. We further note that the magnitude of both increases is larger the higher is $\beta$. Since we have here taken the CP to be relatively precise, an increase in $\beta$ raises the expected transfer to induce a breach by more than the expected to prevent one. The intuition is that the more precise is the CP, the less important becomes the authority's audit with respect to the expected managerial punishment when preventing a breach. Thus, the greater is $\beta$ the more likely it is that the introduction of the reporting constraint increases the expected transfer to induce a breach by more than the expected transfer to prevent one. Since a large cap on the corporate fine $\bar{F}$ allows for a lower equilibrium audit probability $\beta$, we have that it is optimal to grant individual leniency only if and only if $\bar{F}$ is sufficiently low, i.e. only if and only if $\bar{F}<\tilde{F}$.

Finally, suppose $\bar{f}>\tilde{\tilde{f}}$. Absent individual leniency, it is now either very cheap or costless to prevent a breach. In contrast, the greater is $\beta$, the more costly it becomes to induce a breach. Granting individual leniency strictly increases both expected transfers. We note that the attractiveness to the manager of the strategy "breach and blow the whistle" increases with $\beta$ only if the principal induces a breach. Thus, when $\bar{F}>\tilde{\tilde{F}}$, then the audit probability $\beta$ is relatively low, and consequently the attractiveness of the strategy "breach and blow the whistle" is also very low to the manager. As a result, granting leniency leads to an increase in the expected transfer to induce a breach that is smaller by the increase in the expected transfer to prevent a breach: the authority does not grant individual leniency. When $\bar{F}<\tilde{\tilde{F}}$, then the audit probability $\beta$ is relatively high and granting individual leniency makes it very costly for the principal to induce a breach, while keeping her manager silent. The increase in the expected transfer to induce a breach is larger than the increase in the expected transfer to prevent a breach: granting individual leniency is optimal.

\subsection{Individual Leniency and Compliance Programs}

The following Proposition states the interaction between individual leniency and CPs.

Proposition 4 Individual leniency reduces the scope of the welfare detrimental as well as the welfare enhancing effect of compliance programs.

Proof. By Lemmas 3 and 4 and their proof in Appendix B, granting individual leniency introduces reporting constraints. If such a reporting constraint becomes binding, CPs are 
ineffective at reducing the expected transfer, because information asymmetries have become irrelevant.

As the proof indicates, the intuition is straightforward. If the authority grants individual leniency, then it may be the case that the reporting constraint becomes binding, thereby determining the expected transfer. As a result, adopting a $\mathrm{CP}$ would not decrease the expected transfer, since it does not affect the reporting constraint. That is, adopting a CP does not affect the principal's employment cost whenever the reporting constraint binds. Therefore, both the welfare detrimental and welfare enhancing effect of CPs is reduced.

The finding that the welfare enhancing effect of $\mathrm{CP}$ is reduced by individual leniency does not mean that individual leniency has a perverse effect on deterring corporate crime. After all, the authority chooses whether or not to grant individual leniency and would therefore only do so if it helps the authority to deter illegal activities. The result rather implies that individual leniency and CPs are substitute tools to decrease the principal's relative profitability of inducing a breach. Without individual leniency, a CP would be used by the principal to reduce the expected transfer needed to prevent corporate crime, thereby reducing the (costly) audit probability. However, granting individual leniency reduces the audit probability by more through changing the principal's contracting problem.

\section{Policy Implications}

Our findings contradict the Corporate Leniency Program, Individual Leniency Program and US Sentencing Guidelines on several dimensions. In this section, we discuss the relevance of our work for (competition) policy.

Corporate Leniency Program. Both the US and EU Corporate Leniency Program (CLP) allows firms to blow the whistle in exchange for full immunity from legal sanctions for the corporation as well as for the involved employees. Such a 'blanket' covering the entire corporation and its employees has the objective to incentivise employees to report illegal acts to their superiors, so as to file for leniency together (Hammond, 2004). However, we show that such a policy has a perverse effect: breaching the law becomes cheaper for the economic agent executing the illegal act, i.e. the employee. This makes corporate crime more attractive to the corporation as the employee does not need to be heavily compensated (indemnified) by its superiors to breach the law.

This result is particularly relevant for types of corporate crime that do not involve strategic interaction with other conspirators. The blanket covering employees then results in a 
lower expected cost of breaching the law for the entire corporation. However, when the illegal act involves coordination with others, which is the case in, for example, cartels, then our result should be balanced with the impact of the blanket on strategic considerations. Coconspirators anticipate that the blanket reduces the corporation's expected cost of corporate crime, which results in the fear that the corporation files for leniency, thereby ex-ante destabilising the conspiracy. Thus, it is important that competition policy carefully balances the blanket's indirect destabilising effect through strategic interaction with our direct corporate crime stabilising effect by reducing the expected indemnification costs.

The CLP provides full corporate leniency. In contrast, our results suggest that partial corporate leniency is more effective, because it would still incentivise the corporation to come forward, while not reducing the corporate sanction to zero. Hence, partial leniency thus ex-ante destabilises corporate crime more than full leniency. However, in practice it may be extremely difficult to determine the optimal amount of leniency, because the authority needs to estimate the corporation's benefit from the breach, which is different for each (type of) breach. The danger is then that the authority implements a policy granting too little leniency, which makes the CLP ineffective altogether. Therefore, although it is better to grant partial leniency in theory, full leniency may be a practical 'second-best' solution. ${ }^{30}$ Again, we note that for crimes involving strategic interaction, optimal policy should weigh our 'partial leniency' result against ex-ante strategic deterrence considerations.

Individual Leniency Program. The US Individual Leniency Program (ILP) grants the involved employee full immunity from legal sanctions when coming forward with incriminating evidence. When the breach involves strategic interaction with a co-conspirator, such a policy destabilises criminal cooperation as each conspirator fears that the other files for individual leniency. ${ }^{31}$ We show that individual leniency not only entails such 'horizontal destabilisation', but also 'vertical destabilisation'. Individual leniency makes breaching the law more expensive for the employee's superior (the cooperation), as it needs to bribe the employee not to file for individual leniency. This makes breaching the law relatively more expensive for the entire cooperation as a vertical structure.

However, we also show that individual leniency entails a perverse effect. Individual leniency not only increases the cost of a breach for the corporation (through the cost of bribing the employee not to file for leniency), it also increases the cost of preventing a breach for the

\footnotetext{
${ }^{30}$ Spagnolo (2006) states that the number of leniency applications increased twentyfold after revisions in the leniency policy, which included automatic full immunity for the first corporation to self-report. This may suggest that an inappropriate level of partial immunity does not have the desired reporting and deterrence effect.

${ }^{31}$ See, for example, Motta and Polo (2003) and Chen and Rey (2006).
} 
corporation, because the employee must be compensated not to 'breach the law and file for leniency' instead of not breaching the law.

Our results suggest that authorities should only grant individual leniency if the expected managerial fine is either particularly low or particularly high. In practice, however, it may be very difficult to determine the managerial fine perceived by the manager. Providing individual leniency for all types of corporate crime may then be a practical 'second-best' solution, although it entails the perverse effect outlined above and may thus increase the profitability of some types of corporate crime.

Combination $\boldsymbol{C L P}$ and $\boldsymbol{I L P}$. The $I L P$ has been used very rarely in practice (Spagnolo, 2006). Hammond (2004) argues that this is not a sign that the ILP is ineffective: an employee that considers to blow the whistle through the $I L P$ can tell its superior who will then file for leniency on behalf of the entire corporation through the $C L P$, which also covers the employee. ${ }^{32}$ The mere existence of the $I L P$ thus promotes the usage of the CLP. However, the leniency policy as outlined in our paper is more effective. When the employee (corporation) does not receive immunity when the corporation (employee) files for corporate (individual) leniency, then the leniency policy introduces a 'vertical race to the courthouse' between the corporation and the employee.

US Sentencing Guidelines. Although the US Sentencing Guidelines (USSG) recommend a discount on the corporate fine when the corporation had a $\mathrm{CP}$ in place at the time of the infringement, our results do not entail such a discount. The reason is that monitoring through a CP can be used to indeed prevent corporate crime, but also to induce it. However, we do realise that this perverse effect may not always be present. In particular, the perverse effect is less relevant when the shareholder delegates the implementation and execution of the CP to a third party like an in-house or external lawyer that can credibly live up to its reputation. However, such delegation may suffer from (secret) collusion between the lawyer and the employee; these considerations are work-in-progress.

CPs in US vs. EU. Focusing on the monitoring aspect of CPs, we argue that CPs may be beneficial in the fight against corporate crime when individual sanctions are low, but detrimental when individual sanctions are high. Individual sanctions are high in the US, sometimes entailing jail sentences, while individual sanctions are low in the EU, and sometimes even non-existent. Thus, our results suggest that CPs may be more desirable in the EU than in the US.

\footnotetext{
${ }^{32}$ For a theoretical exposition, see Festerling (2005).
} 


\section{Concluding Remarks}

In this paper, we have examined the desirability of the firm's monitoring effort and its impact on optimal (competition) policy. We have stressed that the information obtained by monitoring employees through a $\mathrm{CP}$ may be used to prevent corporate crime, but also to promote corporate crime. Thus, we have argued that corporations having adopted a CP should not automatically qualify for a discount on the corporate fine, which contradict the US Sentencing Guidelines. Also, we have provided arguments that the Corporate Leniency Program may be improved upon by granting partial immunity instead of full immunity to the corporation, while granting no immunity to the involved individuals. Finally, we showed that for some types of corporate crime the Individual Leniency Program entails the perverse effect of actually promoting breaches of the law.

We assumed that a $\mathrm{CP}$ is costless to implement so as to not complicate the analysis with exogenous fixed costs, which would not have an impact on 'marginal behavior'. If the adoption of a CP entails a fixed cost, then the qualitative results remain unchanged; the only difference would be that, in equilibrium, a CP is adopted for less parameter values, because the principal would compare its cost with the reduction in salary cost caused by the CP.

Details of the contract between the principal and the agent are unobservable to the authority. In contrast, one may think of a set-up in which the details of this contract are revealed when the authority audits the firm. This would not change our results as the authority finds out whether a breach has occurred anyway when the firm is audited; additional information about the employment contract would then be redundant information.

Our model takes the manager's private benefit from breaching the law $(G)$ to be a fixed observable variable. An interesting extension would be to take the manager's private benefit as a random variable, which is unobservable to the principal. The resulting equilibrium may then entail some breaches occurring, because managers with a very high private benefit would not be deterred from breaching the law in equilibrium.

An extension of the model presented in this paper is work in progress. We consider a third party in charge of the CP, such as an in-house or external lawyer, who cannot credibly commit to reporting evidence to the authority. This introduces a new tradeoff: (i) the lawyer has reputational concerns, which makes monitoring by the lawyer a priori more credible than monitoring by the shareholder, but (ii) the shareholder must now control two players, i.e. the manager and the lawyer, who may collude against the shareholder. 


\section{A Appendix: Proof Lemma 1 and 2 and Propositions 1 and 2}

\section{A.1 Proof Lemmas 1 and 2}

Proof. Denote by $E_{i}[F]$ and $E_{i}[f]$, respectively, the expected fine faced by the principal and the manager when the manager breaches the law and action $i \in\{N, C, R\}$ is implemented, i.e.
$E_{i}[F]=\left\{\begin{array}{l}\beta F^{N} \\ \beta F^{C} \\ \rho_{\sigma} F^{R}+\left(1-\rho_{\sigma}\right) \beta F^{C}\end{array}\right.$
if $i=N$,
if $i=C$,
if $i=R$,
$E_{i}[f]=\left\{\begin{array}{l}\beta f^{N} \\ \beta f^{C} \\ \rho_{\sigma} f^{R}\end{array}\right.$
if $i=N$,
if $i=C$,
if $i=R$.

The expected fine in case of reporting $(i=R)$ consists of two parts, because (i) with probability $\rho_{\sigma}$ the principal finds evidence and reports in which case the authority imposes fines $F^{R}$ and $f^{R}$, and (ii) with probability $1-\rho_{\sigma}$ the principal finds no evidence in which case the authority audits with probability $\beta$ and imposes fines $F^{C}$ and $f^{C}$.

Contract inducing breaches. If the principal wants to induce breaches of the law, given action $i \in\{N, C, R\}$, the optimal contract is defined as the solution of

$$
\begin{aligned}
\max _{t_{\pi, \sigma}}\left\{\rho_{\pi}-\sum_{\pi=0}^{1} \sum_{\sigma=0}^{1} p_{\pi, \sigma}^{b, i} t_{\pi, \sigma}-E_{i}[F]\right\} & \text { s.t. } \\
t_{\pi, \sigma} \geq 0, & \forall\{\pi, \sigma\}, \\
\sum_{\pi=0}^{1} \sum_{\sigma=0}^{1} p_{\pi, \sigma}^{b, i} t_{\pi, \sigma}-E_{i}[f]+G \geq 0, & \\
\sum_{\pi=0}^{1} \sum_{\sigma=0}^{1}\left(p_{\pi, \sigma}^{b, i}-p_{\pi, \sigma}^{n, i}\right) t_{\pi, \sigma}-E_{i}[f]+G \geq 0 . &
\end{aligned}
$$

By limited liability, the participation constraint is satisfied whenever the incentive compatibility constraint is satisfied. Now, if $E_{i}[f] \leq G$, then $\left(I C_{b}\right)$ is satisfied by setting $t_{\pi, \sigma}=0$, $\forall\{\pi, \sigma\}$ and thus $E_{i}\left[t^{b}\right]=0$ for $i \in\{N, C, R\}$.

If $E_{i}[f]>G$, the cheapest way to satisfy $\left(I C_{b}\right)$ is to make a positive transfer only in either (i) state $\{\pi, \sigma\}=\{1,0\}$ if $i=N$ (there is no CP, so evidence never comes available), and (ii) any state in which $\sigma=1$ if $i \in\{C, R\}$ (signal $\sigma=1$ is a sufficient statistic), for example state $\{\pi, \sigma\}=\{1,1\}$. 
Consider first the case in which $i=N$. Then, setting $t_{\pi, \sigma}=0$ for every state of the world $\{\pi, \sigma\} \neq\{1,0\}$, while setting $t_{10}$ to bind the incentive compatibility constraint, gives $t_{10}=\frac{E_{N}[f]-G}{\rho_{\pi}-\left(1-\rho_{\pi}\right)}$, which, in equilibrium, is paid out with probability $\rho_{\pi}$ and thus $E_{N}\left[t^{b}\right]=$ $\gamma^{N}\left(\beta f^{N}-G\right)$, where $\gamma^{N}=\frac{\rho_{\pi}}{2 \rho_{\pi}-1}$.

Consider now the cases in which $i \in\{C, R\}$. Then, setting $t_{\pi, \sigma}=0$ for every state of the world $\{\pi, \sigma\} \neq\{1,1\}$, while setting $t_{11}$ to bind the incentive compatibility constraint, gives $t_{11}=\frac{E_{i}[f]-G}{\rho_{\pi} \rho_{\sigma}}$, which, in equilibrium, is paid out with probability $\rho_{\pi} \rho_{\sigma}$ and thus $E_{i}\left[t^{b}\right]=$ $E_{i}[f]-G$ if $i \in\{C, R\}$.

Contract preventing breaches. If the principal wants to prevent breaches of the law by action $i \in\{N, C, R\}$, the optimal employment contract is defined as the solution of

$$
\begin{aligned}
& \max _{t_{\pi, \sigma}}\left\{1-\rho_{\pi}-\sum_{\pi=0}^{1} \sum_{\sigma=0}^{1} p_{\pi, \sigma}^{n, i} t_{\pi, \sigma}\right\} \text { s.t. } \\
& t_{\pi, \sigma} \geq 0, \forall \pi, \sigma, \\
& \sum_{\pi=0}^{1} \sum_{\sigma=0}^{1} p_{\pi, \sigma}^{n, i} t_{\pi, \sigma} \geq 0, \\
& \sum_{\pi=0}^{1} \sum_{\sigma=0}^{1}\left(p_{\pi, \sigma}^{n, i}-p_{\pi, \sigma}^{b, i}\right) t_{\pi, \sigma}+E_{i}[f]-G \geq 0 .
\end{aligned}
$$

Again, by limited liability, the participation constraint is satisfied whenever the incentive compatibility constraint is satisfied. Now, if $E_{i}[f]>G$, then $\left(I C_{n}\right)$ is satisfied by setting $t_{\pi, \sigma}=0, \forall\{\pi, \sigma\}$ and thus $E_{i}\left[t^{n}\right]=0$ for $i \in\{N, C, R\}$.

If $E_{i}[f] \leq G$, the cheapest way to satisfy $\left(I C_{n}\right)$ is to make a positive transfer only in the state of the world that is most informative about the law not having been breached, i.e. state $\{\pi, \sigma\}=\{0,0\}$. Setting $t_{\pi, \sigma}=0$ for every state of the world $\{\pi, \sigma\} \neq\{0,0\}$, while setting $t_{00}$ to bind the incentive compatibility constraint, gives:

(i) $t_{00}=\frac{G-E_{N}[f]}{\rho_{-}-\left(1-\rho_{\pi}\right)}$ if $i=N$, which, in equilibrium, is paid out with probability $\rho_{\pi}$ and thus $E_{N}\left[t^{n}\right]=\gamma^{N}\left(G-\beta f^{N}\right)$ if $i=N$.

(ii) $t_{00}=\frac{G-E_{i}[f]}{\rho_{\pi}-\left(1-\rho_{\pi}\right)\left(1-\rho_{\sigma}\right)}$ if $i \in\{C, R\}$, which, in equilibrium, is paid out with probability $\rho_{\pi}$ and thus $E_{i}\left[t^{n}\right]=\gamma^{C}\left(G-E_{i}[f]\right)$ if $i \in\{C, R\}$, where $\gamma^{C}=\frac{\rho_{\pi}}{\rho_{\pi}-\left(1-\rho_{\pi}\right)\left(1-\rho_{\sigma}\right)}$. 


\section{A.2 Proof Proposition 1}

Proof. By Lemmas 1 and 2, for any $i \in\{N, C, R\}$, increasing $f^{i}$ weakly increases $E_{i}\left[t^{b}\right]$ and weakly decreases $E_{i}\left[t^{n}\right]$, thereby weakly relaxing constraint (3). The authority thus optimally sets

$$
f^{N}=f^{C}=f^{R}=\bar{f} .
$$

Also, increasing $F^{N}$ and $F^{C}$ weakly relaxes constraint (3). The authority thus optimally sets

$$
F^{N}=F^{C}=\bar{F} .
$$

We now derive the authority's optimal choice of $F^{R}$. Noting that $\rho_{\sigma} f^{R}+\left(1-\rho_{\sigma}\right) \beta f^{C}>$ $\beta f^{C}$ (because $f^{C}=f^{R}=\bar{f}$ ), we have $E_{R}\left[t^{b}\right] \geq E_{C}\left[t^{b}\right]$ and $E_{R}\left[t^{n}\right] \leq E_{C}\left[t^{n}\right]$ by Lemma 2 .

Principal prevents breach. Suppose the principal adopts a $\mathrm{CP}$ and wishes to prevent a breach. Since $E_{R}\left[t^{n}\right] \leq E_{C}\left[t^{n}\right]$, the principal is better off if she can credibly commit visà-vis the manager to reporting evidence to the authority. Such a commitment also relaxes constraint (3) and is credible if and only if the authority sets $F^{R} \leq \beta F^{C}$.

Principal induces breach. Suppose now the principal adopts a CP and induces a breach. If the authority sets $F^{R}>\beta F^{C}$, the principal will not report evidence when she finds it. If instead $F^{R}<\beta F^{C}$, the principal cannot help but report evidence whenever she finds it. Finally, if the authority sets $F^{R}=\beta F^{C}$, ex-post the principal is ex-post indifferent between reporting evidence or not. However, ex-ante she prefers to commit to not reporting evidence, because that reduces her expected transfer since $E_{C}\left[t^{b}\right] \leq E_{R}\left[t^{b}\right]$. Her expected payoff thus is

$$
\Pi_{i}^{b}= \begin{cases}\Pi^{b, C}=\rho_{\pi}-E\left[t^{b, C}\right]-\beta F^{C} & \text { if } F^{R}>\beta F^{C}, \\ \Pi^{b, C}=\rho_{\pi}-E\left[t^{b, C}\right]-\beta F^{C} & \text { if } F^{R}=\beta F^{C}, \\ \Pi^{b, R}=\rho_{\pi}-E\left[t^{b, R}\right]-\rho_{\sigma} F^{R}-\left(1-\rho_{\sigma}\right) \beta F^{C} & \text { if } F^{R}<\beta F^{C},\end{cases}
$$

Now, moving from $F^{R}=\beta F^{C}$ to $F^{R}<\beta F^{C}$ (i) first entails a discrete downward jump from $\Pi_{C}^{b}$ to $\Pi_{R}^{b}$, because $E_{R}\left[t^{b}\right] \geq E_{C}\left[t^{b}\right]$ and $\rho_{\sigma} F^{R}+\left(1-\rho_{\sigma}\right) \beta F^{C}=\beta F^{C}$ if $F^{R}=\beta F^{C}$, and (ii) second entails a continuous increase in $\Pi_{R}^{b}$, because $\Pi_{R}^{b}$ increases in $F^{R}$. Thus, the authority optimally sets $F^{R}$ slightly under $\beta F^{C}$, that is, $F^{R}=\beta F^{C}-\epsilon$, where $\epsilon$ is arbitrarily small. 


\section{A.3 Proof Proposition 2}

The proof consists of three steps: (i) we derive the optimal audit probability when CPs are available, $\beta^{*}$, (ii) we derive the optimal audit probability when CPs are not available, $\tilde{\beta}^{*}$, and (iii) we compare the relative sizes of $\beta^{*}$ and $\tilde{\beta}^{*}$.

\section{A.3.1 Derive optimal audit probability when CPs are available $\left(\beta^{*}\right)$}

Lemma 1 The optimal audit probability $\beta^{*}$, as a function of $\bar{F}$ and $\bar{f}$, is

$$
\begin{gathered}
\text { If } \bar{f}<G: \beta^{*}= \begin{cases}\emptyset & \text { if } \bar{F}<F_{0}, \\
\frac{\left(2 \rho_{\pi}-1\right) \pi+\gamma^{C}\left(G-\rho_{\sigma} \bar{f}\right)}{\gamma^{C}\left(1-\rho_{\sigma}\right) \bar{f}+\bar{F}} & \text { if } \bar{F}>F_{0},\end{cases} \\
\text { If } \bar{f} \in\left[G, \frac{G}{\rho_{\sigma}}\right]: \beta^{*}= \begin{cases}\emptyset & \text { if } \bar{F}<F_{4}, \\
\frac{\left(2 \rho_{\pi}-1\right) \pi+\left(G-\rho_{\sigma} \bar{f}\right)}{\left(1-\rho_{\sigma}\right) f+\bar{F}} & \text { if } F_{4}<\bar{F}<F_{3}, \\
\frac{\left(2 \rho_{\pi}-1\right) \pi+\gamma^{N} G}{\gamma^{N} f+\bar{F}} & \text { if } F_{3}<\bar{F}<F_{2}, \\
\frac{\left(2 \rho_{\pi}-1\right) \pi}{\bar{F}} & \text { if } F_{2}<\bar{F}<F_{1}, \\
\frac{\left(2 \rho_{\pi}-1\right) \pi+\gamma^{C}\left(G-\rho_{\sigma} \bar{f}\right)}{\gamma^{C}\left(1-\rho_{\sigma}\right) f+\bar{F}} & \text { if } \bar{F}>F_{1},\end{cases} \\
\text { If } \bar{f}>\frac{G}{\rho_{\sigma}}: \beta^{*}= \begin{cases}\emptyset & \text { if } \bar{F}<F_{4}, \\
\frac{\left(2 \rho_{\pi}-1\right) \pi+\left(G-\rho_{\sigma} \bar{f}\right)}{\left(1-\rho_{\sigma}\right) f+\bar{F}} & \text { if } F_{4}<\bar{F}<F_{3}, \\
\frac{\left(2 \rho_{\pi}-1\right) \pi+\gamma^{N} G}{\gamma^{N} f+F} & \text { if } F_{3}<\bar{F}<F_{2}, \\
\frac{\left(2 \rho_{\pi}-1\right) \pi}{\bar{F}} & \text { if } \bar{F}>F_{2},\end{cases}
\end{gathered}
$$

where $F_{0}=\left(2 \rho_{\pi}-1\right) \pi+\gamma^{C}(G-\bar{f}), F_{1}=\frac{\left(2 \rho_{\pi}-1\right) \pi\left(1-\rho_{\sigma}\right) \bar{f}}{\left(G-\rho_{\sigma} \bar{f}\right)}, F_{2}=\frac{\left(2 \rho_{\pi}-1\right) \pi \bar{f}}{G}$, $F_{3}=\frac{\left(\left(2 \rho_{\pi}-1\right) \pi+\gamma^{N} G\right)\left(\gamma^{N}-\left(1-\rho_{\sigma}\right)\right) \bar{f}-\left(\rho_{\sigma} \bar{f}+\left(\gamma^{N}-1\right) G\right) \gamma^{N} \bar{f}}{\left(\rho_{\sigma} \bar{f}+\left(\gamma^{N}-1\right) G\right)}$, and $F_{4}=\left(2 \rho_{\pi}-1\right) \pi+G-\bar{f}$.

Proof. From Lemmas 1 and 2 we know that if the principal prevents a breach, she adopts a $\mathrm{CP}$ and the expected transfer is $E_{R}\left[t^{n}\right]=\max \left\{\gamma^{C}\left(G-\rho_{\sigma} \bar{f}-\left(1-\rho_{\sigma}\right) \beta \bar{f}\right), 0\right\}$. Conversely, if the principal induces a breach, she may or may not adopt a CP, resulting in expected transfer $E_{R}\left[t^{b}\right]=\max \left\{\gamma^{C}\left(\rho_{\sigma} \bar{f}+\left(1-\rho_{\sigma}\right) \beta \bar{f}-G\right), 0\right\}$ or $E_{N}\left[t^{b}\right]=\max \left\{\gamma^{N}(\beta \bar{f}-G), 0\right\}$, respectively.

Thus, the authority's simplified problem is to minimise $\beta$, subject to $\Pi_{R}^{n} \geq \max \left\{\Pi_{N}^{b}, \Pi_{R}^{b}\right\}$, that is,

$$
\left(1-\rho_{\pi}\right) \pi-E_{R}\left[t^{n}\right] \geq \rho_{\pi}-\min \left\{E_{N}\left[t^{b}\right]+\beta \bar{F}, E_{R}\left[t^{b}\right]+\beta \bar{F}-\rho_{\sigma}|\epsilon|\right\},
$$


where we neglect $\epsilon$ for notational convenience,

$$
\left(1-\rho_{\pi}\right) \pi-E_{R}\left[t^{n}\right] \geq \rho_{\pi} \pi-\min \left\{E_{N}\left[t^{b}\right], E_{R}\left[t^{b}\right]\right\}-\beta \bar{F}
$$

The actual formulas for expected transfers $E_{R}\left[t^{n}\right]$ and $\min \left\{E_{N}\left[t^{b}\right], E_{R}\left[t^{b}\right]\right\}$ depend on $\beta$. These formulas are stated in the following table.

\begin{tabular}{|l|l|l|}
\hline & $\begin{array}{l}\text { PREVEnTING BREACH: } \\
E_{R}\left[t^{n}\right]\end{array}$ & $\begin{array}{l}\text { INDUCING BREACH: } \\
\min \left\{E_{N}\left[t^{b}\right], E_{R}\left[t^{b}\right]\right\}\end{array}$ \\
\hline \hline$\beta \in\left[0, \frac{G-\rho_{\sigma} \bar{f}}{\left(1-\rho_{\sigma}\right) \bar{f}}\right]$ & $\gamma^{C}\left(G-\rho_{\sigma} \bar{f}-\left(1-\rho_{\sigma}\right) \beta \bar{f}\right)$ & $E_{N}\left(t^{b}\right)=E_{R}\left[t^{b}\right]=0$ \\
\hline$\beta \in\left[\frac{G-\rho_{\sigma} \bar{f}}{\left(1-\rho_{\sigma}\right) \bar{f}}, \frac{G}{f}\right]$ & 0 & $E_{N}\left(t^{b}\right)=0$ \\
\hline$\beta \in\left[\frac{G}{f}, \frac{\rho_{\sigma} \bar{f}+\left(\gamma^{N}-1\right) G}{\left(\gamma^{N}-\left(1-\rho_{\sigma}\right)\right) \bar{f}}\right]$ & 0 & $E_{N}\left(t^{b}\right)=\gamma^{N}(\beta \bar{f}-G)$ \\
\hline$\beta \in\left[\frac{\rho_{\sigma} \bar{f}+\left(\gamma^{N}-1\right) G}{\left(\gamma^{N}-\left(1-\rho_{\sigma}\right)\right) \bar{f}}, 1\right]$ & 0 & $E_{R}\left(t^{b}\right)=\rho_{\sigma} \bar{f}+\left(1-\rho_{\sigma}\right) \beta \bar{f}-G$ \\
\hline
\end{tabular}

The formulas that expected transfers may take thus depend on $\beta$, but also on $\bar{f}$ and $G$ (since $\beta$ necessarily lies in the $[0,1]$ interval). There are two relevant thresholds for $\bar{f}$ : $G$ and $\frac{G}{\rho_{\sigma}}$.

Suppose $\bar{f}<G$. Only the first row is then relevent since $\frac{G-\rho_{\sigma} \bar{f}}{\left(1-\rho_{\sigma}\right) \bar{f}}>1$. We then have $E_{R}\left[t^{n}\right]=\gamma^{C}\left(G-\rho_{\sigma} \bar{f}-\left(1-\rho_{\sigma}\right) \beta \bar{f}\right)$ and $\min \left\{E_{N}\left[t^{b}\right], E_{R}\left[t^{b}\right]\right\}=E_{N}\left[t^{b}\right]=0$. Substituting these transfers in constraint (7) and solving for $\beta$ gives equation (4), which is smaller than one if and only if $\bar{F}>F_{0}$.

Suppose $\bar{f} \in\left[G, \frac{G}{\rho_{\sigma}}\right]$. All rows of the table are then relevant. For each region of $\beta$ (i.e. for each row of the table), substituting these transfers in constraint (7) and solving for $\beta$ gives equation (5), where the conditions on $\bar{F}$ ensure that the derived solution indeed lies within the relevant region of $\beta$.

Suppose $\bar{f}>\frac{G}{\rho_{\sigma}}$. Only the last three rows of the table are then relevant. For each region of $\beta$ (i.e. for each row of the table), substituting these transfers in constraint (7) and solving for $\beta$ gives equation (6), where the conditions on $\bar{F}$ ensure that the derived solution indeed lies within the relevant region of $\beta$.

\section{A.3.2 Derive optimal audit probability when CPs are not available $\left(\tilde{\beta}^{*}\right)$}

By Lemma 1, the expected transfer is $E_{N}\left[t^{b}\right]=\max \left\{\gamma^{N}\left(\beta f^{N}-G\right), 0\right\}$ when inducing a breach, and $E_{N}\left[t^{n}\right]=\max \left\{\gamma^{N}\left(G-\beta f^{N}\right), 0\right\}$ when preventing a breach. Thus, we have (i) if $G<\beta \bar{f}$ then $E_{N}\left[t^{b}\right]=\gamma^{N}\left(\beta f^{N}-G\right)$ and $E_{N}\left[t^{n}\right]=0$, and (ii) if $G>\beta \bar{f}$ then $E_{N}\left[t^{b}\right]=0$ and $E_{N}\left[t^{n}\right]=\gamma^{N}\left(G-\beta f^{N}\right)$. In both cases, we have $E_{N}\left[t^{n}\right]-E_{N}\left[t^{b}\right]=\gamma^{N}\left(G-\beta f^{N}\right)$. 
The authority minimises $\beta$ subject to $\Pi_{N}^{n} \geq \Pi_{N}^{b}$, that is,

$$
\begin{aligned}
\left(1-\rho_{\pi}\right) \pi-E_{N}\left[t^{n}\right] & \geq \rho_{\pi} \pi-E_{N}\left[t^{b}\right]-\beta \bar{F} \\
\beta \bar{F} & \geq\left(2 \rho_{\pi}-1\right) \pi+E_{N}\left[t^{n}\right]-E_{N}\left[t^{b}\right] .
\end{aligned}
$$

Substituting for $E_{N}\left[t^{n}\right]-E_{N}\left[t^{b}\right]=\gamma^{N}\left(G-\beta f^{N}\right)$ and solving for $\beta$ gives

$$
\tilde{\beta}^{*}= \begin{cases}\emptyset & \text { if } \bar{F}<F_{5}, \\ \frac{\left(2 \rho_{\pi}-1\right) \pi+\gamma^{N} G}{\gamma^{N} \bar{f}+\bar{F}} & \text { if } \bar{F}>F_{5},\end{cases}
$$

where $\bar{F}>F_{5}=\left(2 \rho_{\pi}-1\right) \pi+\gamma^{N}(G-\bar{f})$ ensures that $\tilde{\beta}^{*}$ is indeed smaller than one.

\section{A.3.3 Comparison of $\beta^{*}$ and $\tilde{\beta}^{*}$}

By straightforward algebra, comparing $\beta^{*}$ and $\tilde{\beta}^{*}$ gives:

$\beta^{*}<\tilde{\beta}^{*}$ if (i) $\bar{f}<G$ and $\bar{F}>F_{0}$, or (ii) $\bar{f} \in\left[G, \frac{G}{\rho_{\sigma}}\right]$ and $\bar{F}>F_{2}$, or (iii) $\bar{f}>\frac{G}{\rho_{\sigma}}$ and $\bar{F}>F_{2}$;

$\beta^{*}>\tilde{\beta}^{*}$ if (ii) $\bar{f} \in\left[G, \frac{G}{\rho_{\sigma}}\right]$ and $\bar{F}<F_{3}$, or if (iii) $\bar{f}>\frac{G}{\rho_{\sigma}}$ and $\bar{F}<F_{3}$; and

$\beta^{*}=\tilde{\beta}^{*}$ otherwise.

This is the technical equivalence of Proposition 2, where we define $F^{\prime}=F_{2}$ and $F^{\prime \prime}=F_{3}$.

\section{B Appendix: Proof Lemmas 3 and 4}

This Appendix derives the expected transfers. Denote by $i=E$ the principal's action of "not adopting a CP and blowing the whistle when the manager shows evidence to her". Similar to the results in Section 4, we anticipate that the authority optimally (i) sets the managerial fines $f^{N}, f^{C}$ and $f^{R}$ to their legal maximum $\bar{f}$; (ii) sets the corporate fines $F^{N}$ and $F^{C}$ to their legal maximum $\bar{F}$; and (iii) grants partial corporate leniency when the principal reports evidence to the authority, i.e. $F^{R}=\beta \bar{F}-|\epsilon|$, thereby ensuring that the principal always reports when she has evidence of a breach. We ex-post verify that this anticipation is indeed correct; the proof is long and available on request.

\section{B.1 Expected transfer to prevent a breach}

If the principal prevents a breach, she optimally implements a $\mathrm{CP}$ to monitor the manager, while paying him a positive transfer if and only if $\pi=0, \sigma=0, r_{A}=0$ and $r_{P}=0$. Denoting 
transfers by $t_{\pi, \sigma, r_{A}, r_{P}}$, the principal sets $t_{0,0,0,0} \geq 0$, such that

$$
\begin{aligned}
& \rho_{\pi} t_{0,0,0,0} \geq\left(1-\rho_{\pi}\right)\left(1-\rho_{\sigma}\right) t_{0,0,0,0}+G-\rho_{\sigma} f^{R}-\left(1-\rho_{\sigma}\right) \beta f^{C}, \\
& \rho_{\pi} t_{0,0,0,0} \geq G-f^{r}, \\
& \rho_{\pi} t_{0,0,0,0} \geq G-f^{R}, \\
& \rho_{\pi} t_{0,0,0,0} \geq 0
\end{aligned}
$$

where (8) ensures that the principal does not "breach and not show evidence to the principal and not blow the whistle", (9) ensures that the principal does not "breach and blow the whistle", (10) ensures that the manager does not "breach and show evidence to the principal", and (11) is the participation constraint. We then have

$$
E\left[t^{n}\right]=\rho_{\pi} t_{0,0,0,0}=\max \left\{\gamma^{C}\left(G-\rho_{\sigma} f^{R}-\left(1-\rho_{\sigma}\right) \beta f^{C}\right), G-f^{r}, 0\right\}
$$

\section{B.2 Expected transfer to induce a breach}

When the principal induces a breach, she may do so by (i) adopting a CP or not, and (ii) requesting evidence from the manager or not. ${ }^{33}$ We consider the four possible cases in turn.

\section{B.2.1 CP and no request for evidence}

Suppose the principal adopts a CP and does not request evidence from the manager. She will then use signal $\sigma=1$ to induce a breach, because $\sigma=1$ is a perfectly informative signal of a breach having occurred. The realisation of $\pi$ is then irrelevant. Moreover, the principal must ensure that the manager does not blow the whistle or shows evidence to the principal. Transfers are thus contingent on the realisation of $\sigma, r_{a}$ and $r_{p}$. We denote them by $t_{\sigma, r_{a}, r_{p}}$, such that $t_{\sigma, r_{a}, r_{p}}=0$ if $r_{a}=1$ and $/$ or $r_{p}=1$.

Interim stage. Suppose the manager has breached and signal $\sigma$ is now going to be realised. If $\sigma=1$ the principal blows the whistle and the games ends. However, if $\sigma=0$ the principal must ensure that the manager does not blow the whistle or reports to the principal, which is the case if she compensates him by $t_{0,0,0} \geq \beta f^{C}-\min \left\{f^{r}, f^{R}\right\}$.

Ex-ante stage. To induce the manager to breach the law in the first place, the principal must create a wedge, say $\Delta>0$, between $t_{1,0,0}$ and $t_{0,0,0}$. She optimally does so by setting

\footnotetext{
${ }^{33}$ We assume that $\bar{F}$ is sufficiently large such that the principal never induces a breach by requiring the manager to blow the whistle. Anticipating that the authority sets corporate fines to the maximum, such a strategy would mean being imposed the corporate fine $\bar{F}$ for sure, which is irrational if $\bar{F}$ is large enough.
} 


$$
\begin{aligned}
t_{0,0,0} & =\max \left\{\beta f^{C}-\min \left\{f^{r}, f^{R}\right\}, 0\right\} \text { and } t_{1,0,0}=t_{0,0,0}+\Delta, \text { such that } \\
& \rho_{\sigma}\left(t_{0,0,0}+\Delta\right)+\left(1-\rho_{\sigma}\right) t_{0,0,0}+G-\rho_{\sigma} f^{R}-\left(1-\rho_{\sigma}\right) \beta f^{C} \geq t_{0,0,0}, \\
& \rho_{\sigma}\left(t_{0,0,0}+\Delta\right)+\left(1-\rho_{\sigma}\right) t_{0,0,0}+G-\rho_{\sigma} f^{R}-\left(1-\rho_{\sigma}\right) \beta f^{C} \geq G-\min \left\{f^{r}, f^{R}\right\}, \\
& \rho_{\sigma}\left(t_{0,0,0}+\Delta\right)+\left(1-\rho_{\sigma}\right) t_{0,0,0}+G-\rho_{\sigma} f^{R}-\left(1-\rho_{\sigma}\right) \beta f^{C} \geq 0,
\end{aligned}
$$

where (13) ensures that the manager does not "not breach the law", (14) ensures that the manager does not "breach and blow the whistle or report to the principal", and (15) is the participation constraint, which is implied by (13). We then have by (13) and (14) that

$$
\begin{gathered}
E\left[t^{b}\right]=\rho_{\sigma}\left(t_{0,0,0}+\Delta\right)+\left(1-\rho_{\sigma}\right) t_{0,0,0} \\
=\max \left\{\rho_{\sigma} f^{R}+\left(1-\rho_{\sigma}\right) \beta f^{C}-G+\max \left\{\beta f^{C}-\min \left\{f^{r}, f^{R}\right\}, 0\right\},\right. \\
\left.\rho_{\sigma} f^{R}+\left(1-\rho_{\sigma}\right) \beta f^{C}-\min \left\{f^{r}, f^{R}\right\}, 0\right\} .
\end{gathered}
$$

\section{B.2.2 No CP and no request for evidence}

Suppose the principal does not adopt a CP and does not request evidence from the manager. She will then use signal $\pi=1$ to induce a breach. Moreover, the principal must ensure that the manager does not blow the whistle or reports evidence to the principal. Transfers are thus contingent on the realisation of $\pi, r_{a}$ and $r_{p}$. We denote them by $t_{\pi, r_{a}, r_{p}}$, such that $t_{\sigma, r_{a}, r_{p}}=0$ if $r_{a}=1$ and $/$ or $r_{p}=1$.

Interim stage. Suppose the manager has breached and profit $\pi$ is now going to be realised. The principal then ensures that the manager does not blow the whistle or reports evidence to the principal by paying him $t_{\pi, 0,0} \geq \beta f^{N}-\min \left\{f^{r}, f^{E}\right\}$ for both $\pi \in\{0,1\}$.

Ex-ante stage. To induce the manager to breach the law in the first place, the principal must create a wedge, say $\Delta>0$, between $t_{1,0,0}$ and $t_{0,0,0}$. She optimally does so by setting $t_{0,0,0}=\max \left\{\beta f^{N}-\min \left\{f^{r}, f^{E}\right\}, 0\right\}$ and $t_{1,0,0}=t_{0,0,0}+\Delta$, such that

$$
\begin{aligned}
& \rho_{\pi}\left(t_{0,0,0}+\Delta\right)+\left(1-\rho_{\pi}\right) t_{0,0,0}+G-\beta f^{N} \geq\left(1-\rho_{\pi}\right)\left(t_{0,0,0}+\Delta\right)+\rho_{\pi} t_{0,0,0}, \\
& \rho_{\pi}\left(t_{0,0,0}+\Delta\right)+\left(1-\rho_{\pi}\right) t_{0,0,0}+G-\beta f^{N} \geq G-\min \left\{f^{r}, f^{E}\right\}, \\
& \rho_{\pi}\left(t_{0,0,0}+\Delta\right)+\left(1-\rho_{\pi}\right) t_{0,0,0}+G-\beta f^{N} \geq 0,
\end{aligned}
$$

where (16) ensures that the manager does not "not breach the law", (17) ensures that the manager does not "breach and blow the whistle or report to the principal", and (18) is the participation constraint, which is implied by (16). Noting that (17) is always satisfied, we 
have by (16) that

$$
\Delta=\frac{\beta f^{N}-G}{2 \rho_{\pi}-1},
$$

resulting in expected transfer

$$
\begin{aligned}
E\left[t^{b}\right] & =\rho_{\pi}\left(t_{0,0,0}+\Delta\right)+\left(1-\rho_{\pi}\right) t_{0,0,0} \\
& =\max \left\{\gamma^{N}\left(\beta f^{N}-G\right), 0\right\}+\max \left\{\beta f^{C}-\min \left\{f^{r}, f^{R}\right\}, 0\right\} .
\end{aligned}
$$

\section{B.2.3 CP and request for evidence}

Suppose the principal adopts a $\mathrm{CP}$ and requests evidence from the manager. She can optimally induce a breach by paying the manager a positive transfer if and only if $r_{a}=0$ and $r_{p}=1$. We thus denote the transfers by $t_{r_{a}, r_{p}}$, where $t_{r_{a}, r_{p}}=0$ if $\left(r_{a}, r_{p}\right) \neq(0,1)$.

The principal can request for evidence before or after profit $\pi$ and the outcome of the CP $\sigma$ are realised. Since both pieces of information do not affect the transfers, it does not matter when the principal requests for evidence. She optimally sets $t_{0,1}$ such that

$$
\begin{aligned}
& t_{0,1}+G-f^{R} \geq 0, \\
& t_{0,1}+G-f^{R} \geq G-\rho_{\sigma} f^{R}-\left(1-\rho_{\sigma}\right) \beta f^{C}, \\
& t_{0,1}+G-f^{R} \geq G-f^{r}, \\
& t_{0,1}+G-f^{R} \geq 0,
\end{aligned}
$$

where (19) ensures that the does not "not breach", (20) ensures that the manager does not "breach and not report evidence to the principal", (21) ensures that the manager does not "breach and blow the whistle", and (22) is the participation constraint. The expected transfer is then

$$
E\left[t^{b}\right]=\max \left\{f^{R}-G,\left(1-\rho_{\sigma}\right)\left(f^{R}-\beta f^{C}\right), f^{R}-f^{r}, 0\right\} .
$$

\section{B.2.4 No CP and request for evidence}

Suppose the principal does not adopt a CP, but requests to see the evidence. Again, she optimally induces a breach by paying the manager a positive transfer if and only if $r_{a}=0$ and $r_{p}=1$. We thus denote the transfers by $t_{r_{a}, r_{p}}$, where $t_{r_{a}, r_{p}}=0$ if $\left(r_{a}, r_{p}\right) \neq(0,1)$.

Again, the principal can request for evidence before or after profit $\pi$ and the outcome of the CP $\sigma$ are realised. Since both pieces of information do not affect the transfers, it does 
not matter when the principal requests for evidence. She optimally sets $t_{0,1}$ such that

$$
\begin{aligned}
& t_{0,1}+G-f^{E} \geq 0, \\
& t_{0,1}+G-f^{E} \geq G-\beta f^{N}, \\
& t_{0,1}+G-f^{E} \geq G-f^{r}, \\
& t_{0,1}+G-f^{E} \geq 0,
\end{aligned}
$$

where (23) ensures that the manager does not "not breach the law", (24) ensures that the manager does not "breach and not show evidence to the principal", (25) ensures that the principal does not "breach and blow the whistle", and (25) is the participation constraint. The expected transfer is then

$$
E\left[t^{b}\right]=\max \left\{f^{E}-G, f^{E}-\beta f^{N}, f^{E}-f^{r}, 0\right\} .
$$

\section{B.2.5 Summary of expected transfers to induce a breach}

Substituting $f^{N}=f^{C}=f^{R}=f^{E}=\bar{f}$ into the expected transfers $E\left[t^{b}\right]$ derived above, we arrive at the following table for $E\left[t^{b}\right]$, where $E_{R}[f]=\rho_{\sigma} \bar{f}+\left(1-\rho_{\sigma}\right) \beta \bar{f}$.

\begin{tabular}{|l|l|l|}
\hline & Request For EVIDENCE & Not REQUEST FOR EVIDENCE \\
\hline CP & $\max \left\{\bar{f}-G,\left(1-\rho_{\sigma}\right)(1-\beta) \bar{f}, \bar{f}-f^{r}, 0\right\}$ & $\begin{array}{c}\max \left\{E_{R}[f]-G+\max \left(\beta \bar{f}-f^{r}, 0\right)\right. \\
\left.E_{R}[f]-f^{r}, 0\right\}\end{array}$ \\
\hline No CP & $\max \left\{\bar{f}-G,(1-\beta) \bar{f}, \bar{f}-f^{r}, 0\right\}(\mathrm{X})$ & $\max \left\{\gamma^{N}(\beta \bar{f}-G), 0\right\}+\max \left\{\beta \bar{f}-f^{r}, 0\right\}$ \\
\hline
\end{tabular}

(X) Noting that the strategy "no CP, request for evidence" entails a weakly higher $E\left[t^{b}\right]$ than the strategy "CP, request for evidence", we eliminate the former from the problem.

\section{Appendix: Proof Proposition 3}

This Appendix solves for the optimal managerial leniency policy $f^{r}$, which the authority sets so as to maximise the wedge $E\left[t^{b}\right]-E\left[t^{n}\right]$. Subsections C.1 and C.2, respectively, determine this wedge if $f^{r}=\bar{f}$ and $\bar{f}=0$. We compare those wedges in Subsection B.2.5 so as to derive the optimal $f^{r}$. Throughout the analysis, we assume $\rho_{\sigma}>\frac{1-\rho_{\pi}}{\rho_{\pi}}$ so as to reduce the number of cases.

\section{C.1 No managerial leniency}

Suppose the authority provides no managerial leniency, that is, $f^{r}=\bar{f}$. 
Preventing a breach. If $f^{r}=\bar{f}$ the expected transfer to prevent a breach (12) becomes

$$
E\left[t^{n}\right]=\max \left\{\gamma^{C}\left(G-\rho_{\sigma} \bar{f}-\left(1-\rho_{\sigma}\right) \beta \bar{f}\right), G-\bar{f}, 0\right\},
$$

where the "reporting constraint" $G-\bar{f}$ is irrelevant, because (i) $\gamma^{C}\left(G-\rho_{\sigma} \bar{f}-\left(1-\rho_{\sigma}\right) \beta \bar{f}\right)>$ $G-\bar{f}$ if and only if $\beta<\beta^{l}=\frac{\left(\gamma^{C}-1\right) G-\gamma^{C} \rho_{\sigma} \bar{f}+\bar{f}}{\gamma^{C}\left(1-\rho_{\sigma}\right) \bar{f}}$, where $\beta^{l}>1$ if $\bar{f}<G$ and thus $\beta<\beta^{l}$ holds, while (ii) if instead $\bar{f}>G$, we have $G-\bar{f}<0$. Therefore,

$$
E\left[t^{n}\right]=\max \left\{\gamma^{C}\left(G-\rho_{\sigma} \bar{f}-\left(1-\rho_{\sigma}\right) \beta \bar{f}\right), 0\right\}
$$

Inducing a breach. Substituting $f^{r}=\bar{f}$ in the expressions in Subsection B.2.5 yields

$$
E\left[t^{n}\right]=\min \left\{\max \left(\rho_{\sigma} \bar{f}+\left(1-\rho_{\sigma}\right) \beta \bar{f}-G, 0\right), \max \left\{\gamma^{N}(\beta \bar{f}-G), 0\right\}, 0\right\} .
$$

The wedge. From (27) and (28) we have that the wedge $E\left[t^{b}\right]-E\left[t^{n}\right]$ is the same as in the case in which the manager does not possess evidence, yielding the table on page A.3.1.

\section{C.2 Managerial leniency}

Suppose the authority provides managerial leniency, that is, $f^{r}=0$.

Preventing a breach. If $f^{r}=0$ the expected transfer to prevent a breach (12) becomes

$$
E\left[t^{n}\right]=\max \left\{\gamma^{C}\left(G-\rho_{\sigma} \bar{f}-\left(1-\rho_{\sigma}\right) \beta \bar{f}\right), G, 0\right\},
$$

and the "reporting constraint" $G$ binds if and only if $G>\gamma^{C}\left(G-\rho_{\sigma} \bar{f}-\left(1-\rho_{\sigma}\right) \beta \bar{f}\right)$, that is, if and only if

$$
\beta>\hat{\beta}=\frac{\left(\gamma^{C}-1\right) G-\gamma^{C} \rho_{\sigma} \bar{f}}{\left(1-\rho_{\sigma}\right) \gamma^{C} \bar{f}},
$$

where we note that $\hat{\beta}>0 \Leftrightarrow \bar{f}<\frac{\left(\gamma^{C}-1\right) G}{\gamma^{C} \rho_{\sigma}}$ and $\hat{\beta}<1 \Leftrightarrow \bar{f}>\frac{\left(\gamma^{C}-1\right) G}{\gamma^{C}}$. The following table then summarises the expected transfer needed to prevent a breach depending on $\bar{f}$ and $\beta$. 


\begin{tabular}{|l|l|l|}
\hline Cap on managerial fine $\bar{f}$ & Audit PRob. $\beta$ & Expected transfer $E\left[t^{n}\right]$ \\
\hline \hline $\bar{f} \in\left[0, \frac{\left(\gamma^{C}-1\right) G}{\gamma^{C}}\right]$ & $\beta \in[0,1]$ & $E\left[t^{n}\right]=\gamma^{C}\left(G-\rho_{\sigma} \bar{f}-\left(1-\rho_{\sigma}\right) \beta \bar{f}\right)$ \\
\hline $\bar{f} \in\left[\frac{\left(\gamma^{C}-1\right) G}{\gamma^{C}}, \frac{\left(\gamma^{C}-1\right) G}{\gamma^{C} \rho_{\sigma}}\right]$ & $\beta \in[0, \hat{\beta}]$ & $E\left[t^{n}\right]=\gamma^{C}\left(G-\rho_{\sigma} \bar{f}-\left(1-\rho_{\sigma}\right) \beta \bar{f}\right)$ \\
\cline { 2 - 3 } & $\beta \in[\hat{\beta}, 1]$ & $E\left[t^{n}\right]=G$ \\
\hline $\bar{f} \in\left[\frac{\left(\gamma^{C}-1\right) G}{\gamma^{C} \rho_{\sigma}}, \infty\right)$ & $\beta \in[0,1]$ & $E\left[t^{n}\right]=G$ \\
\hline
\end{tabular}

Inducing a breach. Substituting $f^{r}=0$ in the expressions in Subsection B.2.5 yields

$E\left[t^{b}\right]=\min \left\{\bar{f}, \max \left\{E_{R}[f]-G+\beta \bar{f}, E_{R}[f]\right\}, \max \left\{\gamma^{N}(\beta \bar{f}-G), 0\right\}+\beta \bar{f}, 0\right\}$.

If $\bar{f}<G$ or if $\bar{f}>G$ and $\beta<\frac{G}{f}$, then (29) becomes

$$
E\left[t^{b}\right]=\min \left\{\bar{f}, \rho_{\sigma} \bar{f}+\left(1-\rho_{\sigma}\right) \beta \bar{f}, \beta \bar{f}\right\}=\beta \bar{f} .
$$

If $\bar{f}>G$ and $\beta>\frac{G}{f}$, then we have

$$
E\left[t^{b}\right]=\min \left\{\bar{f}, \rho_{\sigma} \bar{f}+\left(1-\rho_{\sigma}\right) \beta \bar{f}-G+\beta \bar{f}, \gamma^{N}(\beta \bar{f}-G)+\beta \bar{f}\right\},
$$

where we note that

$$
\begin{aligned}
& \gamma^{N}(\beta \bar{f}-G)+\beta \bar{f}<\rho_{\sigma} \bar{f}+\left(1-\rho_{\sigma}\right) \beta \bar{f}-G+\beta \bar{f} \Leftrightarrow \beta<\tilde{\beta}=\frac{\left(\gamma^{N}-1\right) G+\rho_{\sigma} \bar{f}}{\left(\gamma^{N}-\left(1-\rho_{\sigma}\right)\right) \bar{f}}, \\
& \gamma^{N}(\beta \bar{f}-G)+\beta \bar{f}<\bar{f} \Leftrightarrow \beta<\tilde{\tilde{\beta}}=\frac{\gamma^{N} G+\bar{f}}{\left(\gamma^{N}+1\right) \bar{f}}, \text { and } \\
& \rho_{\sigma} \bar{f}+\left(1-\rho_{\sigma}\right) \beta \bar{f}-G+\beta \bar{f}<\bar{f} \Leftrightarrow \beta<\tilde{\tilde{\beta}}=\frac{\left(1-\rho_{\sigma}\right) \bar{f}+G}{\left(2-\rho_{\sigma}\right) \bar{f}},
\end{aligned}
$$

where $0<\tilde{\tilde{\beta}}<\tilde{\tilde{\beta}}<\tilde{\beta}<1$, because $\bar{f}>G$ and by assumption $\rho_{\sigma}>\frac{1-\rho_{\pi}}{\rho_{\pi}}$. Thus,

$$
\begin{gathered}
E\left[t^{b}\right]=\gamma^{N}(\beta \bar{f}-G)+\beta \bar{f} \Leftrightarrow \beta<\tilde{\beta}, \tilde{\tilde{\beta}} \Leftrightarrow \beta<\tilde{\tilde{\beta}}, \\
E\left[t^{b}\right]=\rho_{\sigma} \bar{f}+\left(1-\rho_{\sigma}\right) \beta \bar{f}-G+\beta \bar{f} \Leftrightarrow \beta>\tilde{\beta}, \beta<\tilde{\tilde{\beta}} \text {, which cannot hold, and } \\
E\left[t^{b}\right]=\bar{f} \Leftrightarrow \beta>\tilde{\tilde{\beta}}, \tilde{\tilde{\tilde{\beta}}} \Leftrightarrow \beta>\tilde{\tilde{\beta}} .
\end{gathered}
$$

The following table summarises. 


\begin{tabular}{|c|c|c|}
\hline CAP ON MANAGERIAL FINE $\bar{f}$ & Audit PROB. $\beta$ & EXPECTED TRANSFER $E\left[t^{b}\right]$ \\
\hline $\bar{f} \in[0, G]$ & $\beta \in[0,1]$ & $E\left[t^{b}\right]=\beta \bar{f}$ \\
\hline \multirow[t]{3}{*}{$\bar{f} \in[G, \infty)$} & $\beta \in\left[0, \frac{G}{f}\right]$ & $E\left[t^{b}\right]=\beta \bar{f}$ \\
\hline & $\beta \in\left[\frac{G}{f}, \tilde{\beta}\right]$ & $E\left[t^{b}\right]=\gamma^{N}(\beta \bar{f}-G)+\beta \bar{f}$ \\
\hline & $\beta \in[\tilde{\tilde{\beta}}, 1]$ & $E\left[t^{b}\right]=\bar{f}$ \\
\hline
\end{tabular}

The wedge. Noting that $\frac{\left(\gamma^{C}-1\right) G}{\gamma^{C}}<\frac{\left(\gamma^{C}-1\right) G}{\gamma^{C} \rho_{\sigma}}<G$ by assumption $\rho_{\sigma}>\frac{1-\rho_{\pi}}{\rho_{\pi}}$, the two tables above yield the wedge $E\left[t^{b}\right]-E\left[t^{n}\right]$ outlined in the following table.

\begin{tabular}{|l|l|l|}
\hline CAP on managerial fine $\bar{f}$ & Audit PROB. $\beta$ & WEDGE $E\left[t^{b}\right]-E\left[t^{n}\right]$ \\
\hline \hline $\bar{f} \in\left[0, \frac{\left(\gamma^{C}-1\right) G}{\gamma^{C}}\right]$ & $\beta \in[0,1]$ & $\beta \bar{f}-\gamma^{C}\left(G-\rho_{\sigma} \bar{f}-\left(1-\rho_{\sigma}\right) \beta \bar{f}\right)$ \\
\hline $\bar{f} \in\left[\frac{\left(\gamma^{C}-1\right) G}{\gamma^{C}}, \frac{\left(\gamma^{C}-1\right) G}{\gamma^{C} \rho_{\sigma}}\right]$ & $\beta \in[0, \hat{\beta}]$ & $\beta \bar{f}-\gamma^{C}\left(G-\rho_{\sigma} \bar{f}-\left(1-\rho_{\sigma}\right) \beta \bar{f}\right)$ \\
\cline { 2 - 3 } & $\beta \in[\hat{\beta}, 1]$ & $\beta \bar{f}-G$ \\
\hline \multirow{2}{*}{$\in\left[\frac{\left(\gamma^{C}-1\right) G}{\gamma^{C} \rho_{\sigma}}, G\right]$} & $\beta \in[0,1]$ & $\beta \bar{f}-G$ \\
\hline $\bar{f} \in[G, \infty]$ & $\beta \in\left[0, \frac{G}{f}\right]$ & $\beta \bar{f}-G$ \\
\cline { 2 - 3 } & $\beta\left[\frac{G}{f}, \tilde{\tilde{\beta}}\right]$ & $\gamma^{N}(\beta \bar{f}-G)+\beta \bar{f}-G$ \\
\cline { 2 - 3 } & $\beta \in[\tilde{\beta}, 1]$ & $\bar{f}-G$ \\
\hline
\end{tabular}

\section{C.3 Deriving the optimal $f^{r}$}

Combining the last table above with that on page A.3.1, we have the following table. Comparing the wedge $E\left(t^{b}\right)-E\left(t^{n}\right)$ if $f^{r}=0$ and if $f^{r}=\bar{f}$, the last column states the optimal managerial leniency policy by maximising this wedge. The cells containing numbers in brackets are not straightforward to determine and are therefore derived in more detail below. 


\begin{tabular}{|c|c|c|c|c|}
\hline Fine $\bar{f} \in$ & PROB. $\beta \in$ & WEDGE IF $f^{r}=0$ & WEDGE IF $f^{r}=\bar{f}$ & Optimal $f^{r}$ \\
\hline$\left[0, \frac{\left(\gamma^{C}-1\right) G}{\gamma^{C}}\right]$ & {$[0,1]$} & $\beta \bar{f}-\gamma^{C}\left(G-E_{R}[f]\right)$ & $-\gamma^{C}\left(G-E_{R}[f]\right)$ & 0 \\
\hline \multirow{2}{*}{$\begin{array}{l}{\left[\frac{\left(\gamma^{C}-1\right) G}{\gamma^{C}},\right.} \\
\frac{\left(\gamma^{C}-1\right) G}{\gamma^{C} \rho_{\sigma}}\end{array}$} & {$[0, \hat{\beta}]$} & $\beta \bar{f}-\gamma^{C}\left(G-E_{R}[f]\right)$ & $-\gamma^{C}\left(G-E_{R}[f]\right)$ & 0 \\
\hline & {$[\hat{\beta}, 1]$} & $\beta \bar{f}-G$ & $-\gamma^{C}\left(G-E_{R}[f]\right)$ & $(1)$ \\
\hline$\left[\frac{\left(\gamma^{C}-1\right) G}{\gamma^{C} \rho_{\sigma}}, G\right]$ & {$[0,1]$} & $\beta \bar{f}-G$ & $-\gamma^{C}\left(G-E_{R}[f]\right)$ & $\begin{array}{l}f^{r}=\bar{f} \text { if } \beta<\beta^{\prime \prime} \\
f^{r}=0 \text { if } \beta>\beta^{\prime \prime}\end{array}$ \\
\hline \multirow[t]{5}{*}{$G, \infty$} & $\left.0, \frac{G-\rho_{\sigma} \bar{f}}{\left(1-\rho_{\sigma}\right) f}\right]$ & $\beta \bar{f}-G$ & $-\gamma^{C}\left(G-E_{R}[f]\right)$ & $\bar{f}$ \\
\hline & $\frac{G-\rho_{\sigma} \bar{f}}{\left(1-\rho_{\sigma}\right) f}, \frac{G}{f}$ & $\beta \bar{f}-G$ & 0 & $\bar{f}$ \\
\hline & $\frac{G}{f}, \tilde{\beta}$ & $\gamma^{N}(\beta \bar{f}-G)+\beta \bar{f}-G$ & $\gamma^{N}(\beta \bar{f}-G)$ & 0 \\
\hline & $\tilde{\tilde{\beta}}, \tilde{\beta}$ & $\bar{f}-G$ & $\gamma^{N}(\beta \bar{f}-G)$ & (4) \\
\hline & $\tilde{\beta}, 1$ & $\bar{f}-G$ & $E_{R}[f]-G$ & 0 \\
\hline
\end{tabular}

(1) Granting managerial leniency is optimal iff. $\beta \bar{f}-G>-\gamma^{C}\left(G-\rho_{\sigma} \bar{f}-\left(1-\rho_{\sigma}\right) \beta \bar{f}\right) \Leftrightarrow$

$$
\left(\gamma^{C}\left(1-\rho_{\sigma}\right)-1\right) \bar{f} \beta<\left(\gamma^{C}-1\right) G-\rho_{\sigma} \gamma^{C} \bar{f},
$$

where the LHS is negative by assumption $\rho_{\sigma}>\frac{1-\rho_{\pi}}{\rho_{\pi}}$ and the RHS is positive by $\bar{f}<\frac{\left(\gamma^{C}-1\right) G}{\gamma^{C} \rho_{\sigma}}$. Therefore, (31) holds and thus $f^{r}=0$.

(2) Rewriting (31) gives

$$
\beta>\beta^{\prime \prime}=\frac{\rho_{\sigma} \gamma^{C} \bar{f}-\left(\gamma^{C}-1\right) G}{\rho_{\sigma} \gamma^{C} \bar{f}-\left(\gamma^{C}-1\right) \bar{f}},
$$

where $\beta^{\prime \prime}>1$ if $\bar{f}>G$ and thus it can never be the case that $\beta>\beta^{\prime \prime}$. Therefore, $f^{r}=\bar{f}$.

(3) If $\bar{f}<G$ then $\beta^{\prime \prime}<1$ and thus we have that $f^{r}=0$ if $\beta>\beta^{\prime \prime}$ and $f^{r}=\bar{f}$ if $\beta<\beta^{\prime \prime}$.

(4) We have $\bar{f}-G>\gamma^{N}(\beta \bar{f}-G)$ if and only if

$$
\beta<\beta^{\prime \prime \prime}=\frac{\left(\gamma^{N}-1\right) G+\bar{f}}{\gamma^{N} \bar{f}} .
$$

In this region, we must also have that

$$
\beta<\tilde{\beta}=\frac{\left(\gamma^{N}-1\right) G+\rho_{\sigma} \bar{f}}{\left(\gamma^{N}-\left(1-\rho_{\sigma}\right)\right) \bar{f}}=\frac{\left(\gamma^{N}-1\right) G+\bar{f}-\left(1-\rho_{\sigma}\right) \bar{f}}{\gamma^{N} \bar{f}-\left(1-\rho_{\sigma}\right) \bar{f}},
$$


from which we see that $\tilde{\beta}<\beta^{\prime \prime \prime}$ and thus we have that $\beta<\beta^{\prime \prime \prime}$ in this region. Thus, $f^{r}=0$.

Conclusion on managerial leniency. From the table we see that if $\bar{f} \in[0, \tilde{f}]$, where $\tilde{f}=\frac{\left(\gamma^{C}-1\right) G}{\gamma^{C} \rho_{\sigma}}$, then $f^{r}=0$.

If $\bar{f} \in[\tilde{f}, \tilde{\tilde{f}}]$, where $\tilde{\tilde{f}}=G$, then when $f^{r}=0$, we solve for $\beta$ by solving

$$
\pi-\beta \bar{f}-\beta \bar{F}<1-\pi-G \Leftrightarrow \beta>\frac{2 \pi-1+G}{\bar{F}+\bar{f}} \Rightarrow \beta^{*}=\frac{2 \pi-1+G}{\bar{F}+\bar{f}}
$$

provided that

$$
\beta^{*}>\beta^{\prime \prime} \Leftrightarrow \tilde{F}<\frac{2 \pi-1+G}{\beta^{\prime \prime}}-\bar{f}
$$

If $\bar{f} \in[\tilde{\tilde{f}}, \infty)$, then when $f^{r}=\bar{f}$, we solve for $\beta$ by solving

$$
\pi-\beta \bar{f}-\beta \bar{F}<1-\pi-G \Leftrightarrow \beta>\frac{2 \pi-1+G}{\bar{F}+\bar{f}} \Rightarrow \beta^{*}=\frac{2 \pi-1+G}{\bar{F}+\bar{f}}
$$

provided that

$$
\beta^{*}<\frac{G}{\bar{f}} \Leftrightarrow \tilde{\tilde{F}}>\frac{(2 \pi-1) \bar{f}}{G}
$$

\section{References}

[1] Aubert, C. (2009). Managerial Effort Incentives and Market Collusion. Toulouse School of Economics Working Paper 09-127.

[2] Aubert, C., Kovacic W. and P. Rey. (2006). The Impact of Leniency and Whistleblowing Programs on Cartels. International Journal of Industrial Organization 24(6), 1241-1266.

[3] Arlen, J.H. (1994). The Potentially Perverse Effects of Corporate Criminal Liability. Journal of Legal Studies 23(2), 832-867.

[4] Becker, G.S. (1968). Crime and Punishment: An Economic Approach. Journal of Political Economy 76(2), 169-217.

[5] Bester, H. and R. Strausz. (2001). Contracting with Imperfect Commitment and the Revelation Principle: The Single Agent Case. Econometrica 69(4), 1077-1098.

[6] Chen, Z. and P. Rey. (2006). On the Design of Leniency Programs. IDEI Working Papers 452, Toulouse. 
[7] Dewatripont, M. (1988). Commitment through Renegotiation-Proof Contracts with Third Parties. Review of Economic Studies 55(3), 377-389.

[8] Dickens, W.T, Katz, L.F., Lang, K. and L.H. Summers. (1989). Employee Crime and the Monitoring Puzzle. Journal of Labor Economics 7(3), 331-347.

[9] Fershtman, C. and K.L. Judd. (1987). Equilibrium Incentives in Oligopoly. The American Economic Review 77(5), 927-940.

[10] Hammond, S.D. (2004). Cornerstones of an Effective Leniency Program. U.S. Department of Justice, available for download from http://www.usdoj.gov/.

[11] Harrington Jr., J.E. (2008). Optimal Corporate Leniency Programs. Journal of Industrial Economics 56(2), 215-246.

[12] Healy, P.M. (1985). The Effect of Bonus Schemes on Accounting Decisions. Journal of Accounting and Economics 7(1-3), 85-107.

[13] Hiriart, Y, and D. Martimort. (2006). The Benefits of Extended Liability. The RAND Journal of Economics 37(2), 562-582.

[14] Hiriart, Y., Martimort, D. and J. Pouyet. (2009). The Public Management of Risk: Separating Ex Ante and Ex Post Monitors. PSE Working Papers 2009-20, PSE.

[15] Inderst, R. and M. Ottoviani. (2009). Misselling through Agents. The American Economic Review 99(3), 883-908.

[16] Langevoort, D.C. (2002). The Behavioral Economics of Corporate Compliance With Law. Columbia Business Law Review, 71-118.

[17] Kaplow, L. and S. Shavell. (1994). Optimal Law Enforcement with Self-Reporting of Behavior. Journal of Political Economy 102(3), 583-606.

[18] Khalil, F. (1997). Auditing Without Commitment. The RAND Journal of Economics 28(4), 629-640.

[19] Khanna, V.S. (1996). Corporate Criminal Liability: What Purpose Does it Serve? Harvard Law Review 109(7), 1477-1534.

[20] Miller, N.H. (2009). Strategic Leniency and Cartel Enforcement. The American Economic Review $99(3), 750-768$.

[21] Motta, M. and M. Polo. (2003). Leniency Programs and Cartel Prosecution. International Journal of Industrial Organization 21(3), 347-379. 
[22] Polinsky, A. M. and S. Shavell. (1979). The Optimal Tradeoff between the Probability and Magnitude of Fines. The American Economic Review 69(5), 880-891.

[23] Polinsky, A. M. and S. Shavell. (1992). Enforcement Costs and the Optimal Magnitude and Probability of Fines. Journal of Law \& Economics 35(1), 133-148.

[24] Polinsky, A. M. and S. Shavell. 1993. Should Employees be Subject to Fines and Imprisonment Given the Existence of Corporate Liability? International Review of Law and Economics 13(3), 239-257.

[25] U.S. Sentencing Guidelines Manual §§ 8C2.5(f), 8C2.6 (2001).

[26] Aggarwal, R.K. and A.A. Samwick. (1999). Executive Compensation, Strategic Competition, and Relative Performance Evaluation: Theory and Evidence. Journal of Finance 54(6), 19992043.

[27] Schmidt, K.M. (1997). Managerial Incentives and Product Market Competition. Review of Economic Studies 64(2), 191-213.

[28] Segerson, K. and T. Tietenberg. (1992). The Structure of Penalties in Environmental Enforcement: An Economic Analysis. Journal of Environmental Economics and Management 23(2), 179-200.

[29] Shavell, S. (1984). A Model of the Optimal Use of Liability and Safety Regulation. The RAND Journal of Economics 15(2), 271-280.

[30] Shavell, S. (1997). The Optimal Level of Corporate Liability Given the Limited Ability of Corporations to Penalize Their Employees. International Review of Law and Economics 17(2), 203-213.

[31] Spagnolo, G. (2000). Stock-Related Compensation and Product-Market Competition. The RAND Journal of Economics 31(1), 22-42.

[32] Spagnolo, G. (2006). Leniency and Whistleblowers in Antitrust. CEPR Wokring Paper Series No. 5794 .

[33] Sklivas, S.D. (1987). The Strategic Choice of Managerial Incentives. The RAND Journal of Economics 18(3), 452-458.

[34] Scharfstein, D. (1988). Product-Market Competition and Managerial Slack. The RAND Journal of Economics 19(1), 147-155.

[35] Price Waterhouse Coopers. (2009). 2009 Global Economic Crime Survey: Economic Crime in a Downturn. Available at http://www.pwc.com/. 
[36] U.S. Environmental Protection Agency (1995). Final Statement, Incentives for Self-Policing: Discovery, Disclosure, Correction and Prevention of Violations. 60 Fed. Reg. 66,706 (December $22,1995)$.

[37] U.S. Department of Justice Antitrust Division. Corporate Leniency Policy (August 10, 1993), 328 Trade Reg. Rep 20,649-21 (August 16, 1994).

[38] Stephan, A. (2009). Hear no Evil, See no Evil: Why Antitrust Compliance Programmes may be Ineffective at Preventing Cartels. CCP Working Paper 09-9.

[39] Sykes, A.O. (1984). The Economics of Vicarious Liability. Yale Law Journal 93(7), 1231-1280.

[40] Tirole, J. (1986). Hierarchies and Bureaucracies: On the Role of Collusion in Organizations. Journal of Law, Economics and Organization 2(2), 181-214.

[41] Webb, D.K. and S.F. Molo. (1993). Some Practical Considerations in Developing Effective Compliance Programs: A Framework for Meeting the Requirements of the Sentencing Guidelines. Washington University Law Quarterly 71, 375-396. 